AUTARQUIA ASSOCIADA A UNIVERSIDADE DE SÃO PAULO

\title{
MÉTODOS PARA IMPLEMENTAÇÃO DA DOSIMETRIA IN VIVO (DOSE DE ENTRADA) COM DOSÍMETROS TERMOLUMINESCENTES NA RADIOTERAPIA EXTERNA COM FEIXE DE FÓTONS
}

CRISTIANE BARSANELLI

Dissertação apresentada como parte dos requisitos para obtenção do Grau de Mestre em Ciências na Área de Tecnologia Nuclear - Aplicações.

Orientadora:

Dra. Laura Natal Rodrigues

São Paulo 2006 
INSTITUTO DE PESQUISAS ENERGÉTICAS E NUCLEARES

Autarquia associada à Universidade de São Paulo

MÉTODOS PARA IMPLEMENTAÇÃO DA DOSIMETRIA IN VIVO (DOSE DE ENTRADA) COM DOSIMMETROS TERMOLUMINESCENTES NA RADIOTERAPIA EXTERNA COM FEIXE DE FÓTONS

CRISTIANE BARSANELLI

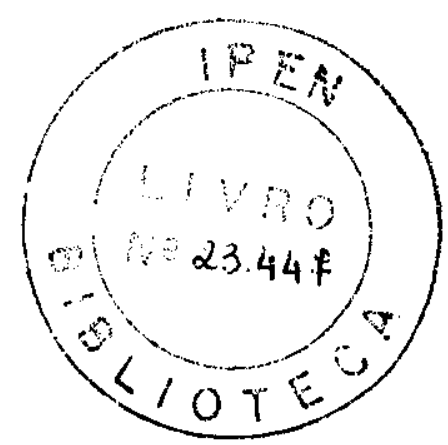

Dissertação apresentada como parte dos requisitos para obtenção do Grau de Mestre em Ciências na Área de Tecnologia Nuclear - Aplicações.

Orientadora:

Dra. Laura Natal Rodrigues 
Dedico este trabalho aos meus pais, Luiz Natal Barsanelli e Sonia Catarina Januário Barsanelli, pelo apoio incondicional, a minha irmã Claudia Barsanelli Costa e ao meu cunhado Luís Henrique Chechinato Costa pelo incentivo constante, e aos amigos do mestrado por toda a ajuda, discussões enriquecedoras e pelos vários momentos de descontração. 


\section{AGRADECIMENTOS}

A minha orientadora, Dra. Laura Natal Rodrigues, que tem me orientado desde o trabalho final da graduação, sempre prestativa e disposta a ajudar. Posso referenciá-la como sendo a pessoa que mais tem contribuído para a minha formação profissional. Obrigada pelo incentivo e encorajamento nos momentos mais delicados e pela confiança enorme em mim depositada.

A Dra. Letícia Lucente Campos Rodrigues, pelo auxílio técnico, uso de equipamentos e livre acesso aos laboratórios do Centro de Metrologia das Radiações do IPEN.

À física chefe do serviço de radioterapia do Hospital Sírio Libanês, Cecília Kalil Haddad, pela oportunidade do estágio realizado, durante o qual pude realizar todas as medidas envolvidas neste trabalho, e à sua equipe de físicos Aluísio, Anselmo, Edílson e Eliana, sempre muito solícitos.

Aos queridos amigos aprimorandos de fisica-médica do Hospital Sírio Libanês, Hélio e Vinícius (Bill), a quem eu recorria com freqüência para discutir as inúmeras dúvidas que surgiram durante a realização do trabalho.

À Dra. Larissa, pelo carinho e atençào com que sempre me tratou, e por ter solicitado a colaboração das pacientes para a realização das medidas in vivo, bem como por ter me acompanhado na realizaçào das mesmas.

Aos técnicos do HSL, Adriana, Antônio, Benedito, Carlos, Cristina, Elisabete, Hedi, Lúcia, Luques, Marcos, Marlene, Nilton, Quitéria, Rosana, Silvana e Wesley, sempre muito prestativos.

Aos amigos conquistados durante essa importante fase da minha vida profissional, André, Eduardo, Juan, Maíra, Márcio, Patrícia e Priscilla, pelo companheirismo, longas conversas e muitas risadas. 
À equipe de usinagem da oficina mecânica do IPEN, pelo trabalho preciso na confecção do objeto simulador utilizado para seleção dos dosímetros.

Ao $\mathrm{CNPq}$ pelo auxilio concedido, o que possibilitou dedicação exclusiva ao trabalho de pesquisa. 


\section{MÉTODOS PARA IMIPLEMENTAÇÃO DA DOSIMETRIA IN VIVO (DOSE DE ENTRADA) COM DOSÍMETROS TERMOLUMINESCENTES NA RADIOTERAPIA EXTERNA COM FEIXE DE FÓTONS}

\section{Cristiane Barsanelli}

\section{RESUMO}

Neste trabalho, estão descritos os métodos de seleção, calibração e de determinação dos fatores de correção, as características fisicas dos dosímetros termoluminescentes, o procedimento de cálculo para converter a leitura do dosímetro em dose absorvida e a metodologia para se determinar a dose de entrada. Foram investigadas a praticidade e a utilidade das medidas de dose de entrada com os dosímetros termoluminescentes, bem como a exatidão e a reprodutibilidade no fornecimento da dose diária. As medidas de dose de entrada foram realizadas em cinco pacientes com diagnóstico de câncer de mama tratadas com um feixe de fótons de $6 \mathrm{MV}$. Năo foram detectados grandes desvios entre a dose medida e a dose esperada (os valores concordaram em $\pm 5 \%$ ), devido à excelente estabilidade do equipamento de tratamento, ao sistema automático de verificação e à boa exatidão no ajuste diário do tratamento. Uma boa precisão pode ser alcançada quando os fatores de correção para cada parâmetro de influência na resposta do dosimetro são cuidadosamente determinados e aplicados para converter o sinal termoluminescente em dose absorvida. O estudo demonstrou a viabilidade do uso dos dosímetros termoluminescentes para a dosimetria in vivo e sua utilidade como parte de um programa de garantia de qualidade em um serviço de radioterapia. 


\title{
METHODS FOR IMPLEMENTATION OF IN VIVO DOSIMETRY (ENTRANCE DOSE) USING TERMOLUMINESCENT DOSIMETERS DURING RADIOTHERAPY TREATMENT WITH PHOTON BEAM
}

\section{Cristiane Barsanelli}

\begin{abstract}
Selection, calibration procedure to convert TLD signal into absorbed dose and physical characteristics of the thermoluminescent dosimeters, as well as the determination of correction factors and the methodology to determine expected entrance dose, are described in this work. Practical aspects and the utility of entrance dose measures with termoluminescentes dosimeters were investigated, as well as the exactness and the reproducibility of the daily dose release. The entrance dose measures were performed in five patients with diagnosis of breast cancer treated with a $6 \mathrm{MV}$ photon beam. The measured dose and the expected dose values agreed in $\pm 5 \%$, due to excellent treatment equipment stability, to automatic verification system and the good exactness in the daily treatment adjustment. Good precision can be achieved when the correction factors for each parameter of influence in the dosimeter response are carefully determined and applied to convert the termoluminescent signal into absorbed dose. The study demonstrates the viability of termoluminescent dosimeters use for in vivo dosimetry and its utility as part of a quality assurance program in a radiation therapy service.
\end{abstract}




\section{SUMÁRIO}

Página

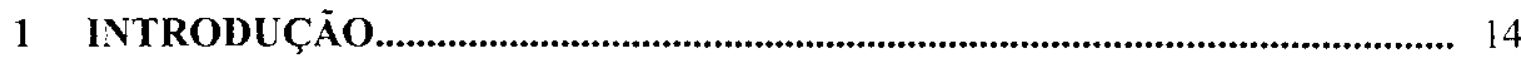

1.1 Considerações gerais................................................................................ 14

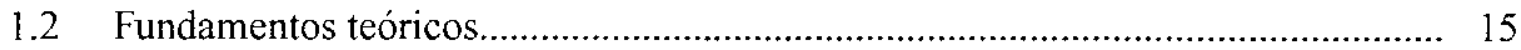

1.2.1 Medida in vivo da dose de entrada................................................................. 15

1.2.2 Dosimetria termoluminescente..................................................................... 16

1.2.3 Dosimetros termoluminescentes................................................................... 19

1.2.3.1 Características dosimétricas do LiF:Mg,Ti (TLD-100) ................................. 20

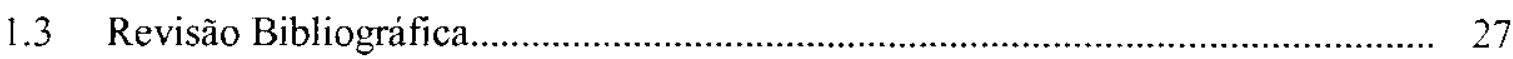

1.3.1 Protocolos ESTRO "booklet" nr. 1 e "booklet" nr. 5 ......................................... 31

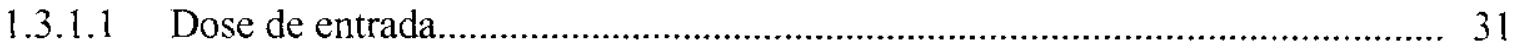

1.3.1.2 Dosímetros termoluminescentes.............................................................. 32

1.3.1.3 Capa de equilibrio eletrônico................................................................. 33

1.3.1.4 Calibração dos dosímetros termoluminescentes........................................... 33

1.3.1.5 Determinação dos fatores de correção........................................................ 34

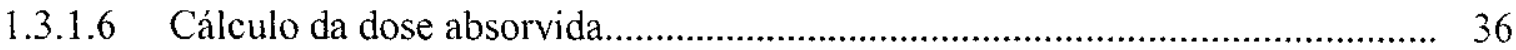

1.3.1.7 Interpretação da medida.................................................................... 37

1.3.1.8 Avaliação dos dados da dosimetria in vivo............................................... 39

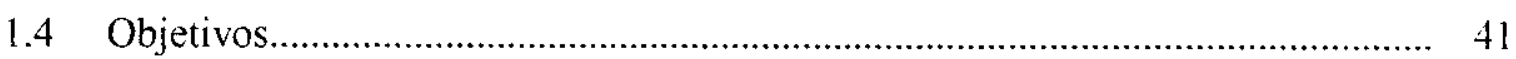

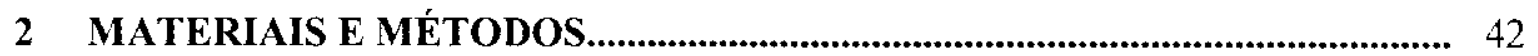

2.1 Dosímetros termoluminescentes................................................................. 42

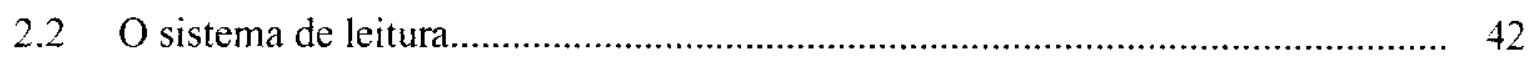

2.3 Procedimento de seleção dos TLDs..................................................................... 43

2.4 Capa de equilíbrio eletrônico......................................................................... 45

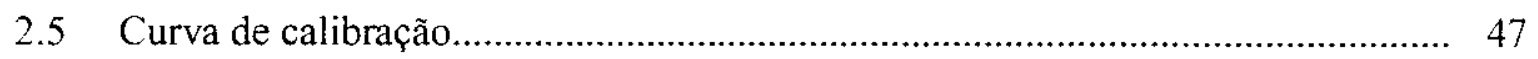

2.6 Procedimento de calibraçào dos TLDs............................................................. 47

2.7 Determinação dos fatores de correção.............................................................. 48

2.8 Seleção dos objetos simuladores................................................................... 48

2.9 Medidas em objetos simuladores........................................................... 50

2.10 Unidades de tratamento ........................................................................ 51

2.11 Técnica de tratamento e planejamento da dose............................................... 52 


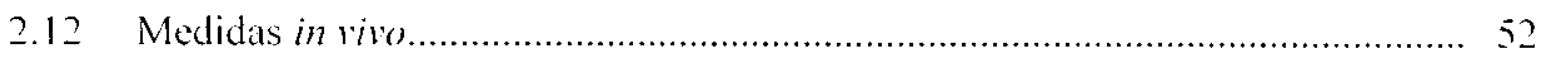

2.13 Determinação da dose de entrada planejada.................................................... 54

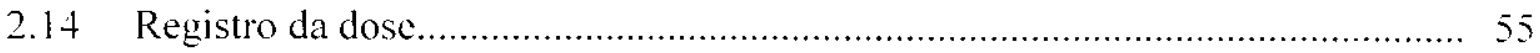

3 RESULTADOS E DISCUSSÕES................................................................... 56

3.1 Seleção dos dosímetros termoluminescentes....................................................... 56

3.2 Estudo da atenuação da capa de equilibrio eletrônico.............................................. 59

3.3 Calibração e fatores de correção........................................................................... 60

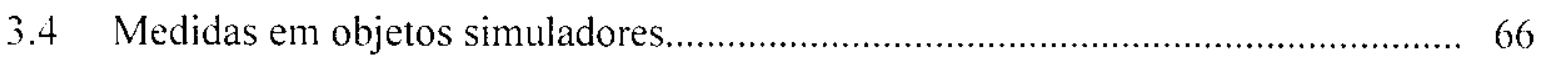

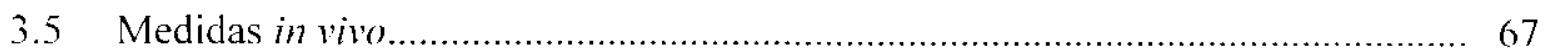

3.6 Estimativa das incertezas........................................................................... 70

3.6.1 Precisão individual do TLD........................................................................ 70

3.6.2 Incerteza na determinação dos fatores de calibração e de correção...................... 71

3.6.3 Incerteza na determinaçâo da dose absorvida medida (TLD)............................ 71

3.6.4 Incerteza na determinação da dose absorvida esperada (TPS) ........................... 71

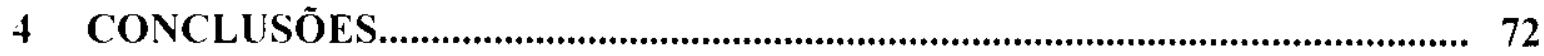

REFERÊNCIAS BIBLIOGRÁFICAS............................................................... 73 


\section{LIST A DE FIGURAS}

Página

FIGURA 1 - Modelo de bandas de energia para um cristal ideal (a) e um cristal real (b). Fonte - Mackinlay, 1981

FIGURA 2 - Modelo de bandas de energia para a termoluminescência. Fonte Mackinlay, 1981

FIGURA 3 - Desenho esquemático da curva de emissão do LiF:Mg,Ti. O formato de cada pico de emissão foi calculado matematicamente. Fonte - Metcalfe et al., 1997. FIGURA 4 - Comportamento da resposta TL do LiF:Mg,Ti em função da dose. Fonte Metcalfe et al., 1997.

FIGURA 5 - Representação esquemática das diferentes doses envolvidas na dosimetria in vivo para aplicação de um único feixe de fótons. Fonte - Van Dam e Marinello, 1994.

FIGURA 6 - Representação esquemática para determinaçào do fator de calibração de dose de entrada de um dosímetro. Fonte - Huyskens et al., 2001

FIGURA 7 - Leitora TL Harshaw Modelo 3500TLD. Fonte - Manual Harshaw 3500TLD.

FIGURA 8 - Capa de equilíbrio eletrônico confeccionada com resina epóxi

FIGURA 9 - Estrutura química do polimero epóxi. Fonte - Wikipédia, a enciclopédia livre

FIGURA 10 - Placa de acrílico utilizada para posicionamento dos TLDs em furos durante o processo de seleção das pastilhas.

FIGURA 11 - Objeto simulador de mama sobre objeto simulador de acrílico.

FIGURA 12 - TLD dentro da capa de equilibrio eletrônico fixado na pele das cinco pacientes no campo interno de tratamento

FIGURA 13 - Ilustração do método utilizado para determinação da dose de entrada para o caso no qual o eixo central do campo de tratamento se encontra bloqueado......... 54

FIGURA 14 - Planilha Excel elaborada para registro das medidas in vivo..................... 55

FIGURA 15 - Atenuação da dose produzida pela capa de equilibrio eletrônico. Os perfis foram obtidos na direção $\mathrm{x}$ do sistema de coordenadas do campo de radiação...... FIGURA 16 - Atenuação da dose produzida pela capa de equilibrio eletrônico. Os perfis foram obtidos na direção y do sistema de coordenadas do campo de radiação...... 
FIGURA 17 - Variação da resposta TL com a dose absorvida........

FIGURA 18 - Variação dos fatores de correçào em funçào do tamanho de campo para as unidades de tratamento MX-2 (a) e KD-2 (b)...

FIGURA 19 - Variação dos fatores de correção em função da DFS para as unidades de tratamento $\mathrm{MX}-2$ (a) e KD-2 (b)

FIGURA 20 - Variação dos fatores de correção em função do àngulo de incidência do feixe para as unidades de tratamento MX-2 (a) e KD-2 (b). 


\section{LISTA DE TABELAS}

Página

TABELA 1 - Constituiçăo isotópica do TLD-100, 600 e 700 (Harshaw)........................ 19

TABELA 2 - Propriedades do TLD-100 .................................................................. 19

TABELA 3 - Características dos picos de emissão do LiF:Mg,Ti................................. 21

TABELA 4 - Verificações regulares no sistema TLD ................................................... 26

TABELA 5 - Niveis de ação e tolerância estabelecidos para diferentes regiões de tratamento.

TABELA 6 - Parâmetros dos tratamentos simulados no objeto simulador de mama.

TABELA 7 - Leitura média e desvio padrão percentual das cinco leituras individuais dos cento e cinqüenta dosímetros termoluminescentes

TABELA 8 - Fatores de calibração e desvios padrão percentuais das leituras dos TLDs calibrados

TABELA 9 - Variação da resposta termoluminescente em função da dose absorvida para diferentes unidades monitoras fornecidas..

TABELA 10 - Valores dos fatores de correção em função do tamanho de campo.

TABELA 11 - Valores dos fatores de correção em função da distância fonte-superfície. 65

TABELA 12 - Valores dos fatores de correção em função do ângulo de incidência do feixe.

TABELA 13 - Valores dos fatores de correção em função do ângulo do filtro físico.

TABELA 14 - Comparação entre a dose de entrada medida com o dosímetro TL e a dose calculada pelo sistema de planejamento por meio do recurso de dose pontual........ 67

TABELA 15 - Parâmetros de tratamento do campo interno das cinco pacientes. 68

TABELA 16 - Fatores de Correção aplicados às medidas de dose de entrada in vivo com TLD nas cinco pacientes.

TABELA 17 - Comparação entre os valores das doses medidas (TLD) e calculadas (TPS) nos três dias consecutivos de medidas - paciente 1

TABELA 18 - Comparação entre os valores das doses medidas (TLD) e calculadas (TPS) nos três dias consecutivos de medidas - paciente 2

TABELA 19 - Comparação entre os valores das doses medidas (TLD) e calculadas (TPS) nos três dias consecutivos de medidas - paciente 3 
TABELA 20 - Comparação entre os valores das doses medidas (TLD) e calculadas

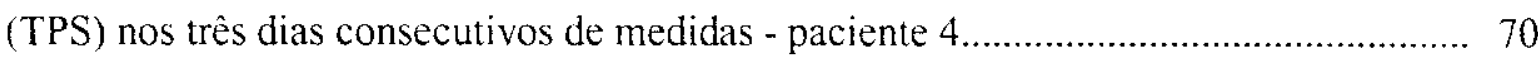

TABELA 21 - Comparação entre os valores das doses medidas (TLD) e calculadas (TPS) nos três dias consecutivos de medidas - paciente 5 . 


\section{LISTA DE ABREVIATLRAS E SIGLAS}

AAPM American Association of Physicists in Medicine

CI Càmara de ionização

Dentrada Dose de entrada

DFS Distância fonte-superficie

$\mathrm{d}_{\max } \quad$ Profundidade de dose máxima

ESTRO European Society for Therapeutic Radiology and Oncology

$\mathrm{F}_{\mathrm{cal}} \quad$ Fator de calibração

FC Fator de correção

$\mathbf{F}_{\mathbf{D}} \quad$ Fator de correção para desvanecimento

$\mathbf{F}_{\mathrm{E}} \quad$ Fator de correção para energia

$\mathbf{F}_{\mathrm{L}} \quad$ Fator de correção para linearidade

FSC Fossa supraclavicular

ICRU International Commission on Radiation Units and Measurements

IMRT Terapia com feixe de intensidade modulada

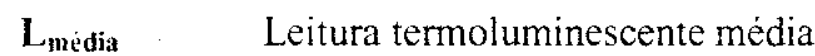

$\mathbf{L}_{\mathrm{CI}} \quad$ Leitura com a câmara de ionizaçào

$\mathbf{L}_{\text {entrada }} \quad$ Leitura de entrada

$\mathbf{L}_{\mathrm{i}} \quad$ Leitura do i-ésimo dosímetro termoluminescente

LiF Fluoreto de Lítio

LTLD Leitura do dosímetro termoluminescente

NACP Nordic Association for Clinical Physics

$\sigma \quad$ Desvio padrào

$\mathrm{S}_{\mathbf{i}} \quad$ Fator de sensibilidade

TLD Dosímetro termoluminescente

TL Termoluminescente

TPS Sistema de planejamento do tratamento

$\mathbf{Z}_{\mathrm{eff}} \quad$ Número atômico efetivo

UM Unidade Monitora

UV Ultravioleta 


\section{INTRODUÇÃO}

\subsection{Considerações Gerais}

O Comitê Internacional de Unidades e Medidas de Radiação (ICRU) estabeleceu, em 1976, que "todos os procedimentos envolvidos no planejamento e na execução da radioterapia podem contribuir para uma incerteza significativa na dose administrada no paciente. Um teste definitivo do tratamento liberado só pode ser feito pela utilização da dosimetria in vivo". A incerteza total em todos esses procedimentos pode ser considerada a máxima exatidão alcançada na liberação da dose. Os valores máximos recomendados para a incerteza na dose variam de $\pm 5 \%$ (ICRU Report 24) a $\pm 3.5 \%$ (1 desvio padrào - $\sigma$ ) (Mijnheer et al, 1987). Entretanto, para cada paciente, a exatidão real na dose fornecida pode ser menor que a desejada devido à variação dos contornos do paciente, à heterogeneidade da região, e ao movimento dos órgãos. Ainda, os erros podem ser introduzidos durante a transferència dos dados do sistema de planejamento do tratamento, TPS, ou do simulador para o acelerador; podem ocorrer nos ajustes do equipamento de tratamento, ou no posicionamento do paciente e modificadores do feixe. A verificação final na dose real fornecida a cada paciente pode somente ser realizada por meio da dosimetria in vivo. A medida in vivo da dose é recomendada por várias organizações internacionais (AAPM, ICRU e NACP).

Na publicação 24 do ICRU (1976) são especificados quais são os parâmetros que a dosimetria in vivo deve incluir, tais como: medidas de dose de entrada, medidas de dose de saida, medidas de transmissão e medidas de dose intra-cavitária. Geralmente, a dosimetria in yivo é limitada a medidas na superfície do paciente, conseguindo-se realizar os três primeiros objetivos citados anteriormente. No entanto, é possivel obter informação relativa à dose no tumor ou em estruturas críticas também por medidas intra-cavitárias (Lindskoug and Lundberg 1984) ou então utilizando a informação combinada das medidas de dose de entrada e de saida para uma estimativa da dose absorvida no tumor (Leunens et al 1990). 
Os tipos de dosímetros comumente empregados na dosimetria in vivo são os diodos e os dosímetros termoluminescentes (TLDs). Os dosimetros termoluminescentes têm sido amplamente utilizados na radioterapia para medir a dose absorvida liberada nos pacientes submetidos a tratamentos radioterápicos (Rudén, 1971; Suntharalingam e Mansfield, 1971; Rudén e Nilsson, 1973). As suas aplicações típicas são a avaliação da dose em órgãos criticos assim como medidas em geometrias dificeis. $\mathrm{Na}$ prática clinica, o material geralmente utilizado é o LiF:Mg,Ti (Fluoreto de Lítio dopado com Magnésio e Titânio). Este material tem uma equivalência bastante apropriada ao tecido $\left(Z_{\mathrm{eff}}=8,3\right)$ e pode ser produzido nas formas desejadas tais como pó, bastões ou discos com dimensões pequenas, da ordem de alguns milimetros. A sua pequena dependência com a taxa de dose, temperatura e energia no intervalo de abrangência da radioterapia fazem com que esse tipo de dosimetro seja apropriado para medida de dose in vivo. A principal vantagem dos TLDs sobre os diodos é que não precisam ser conectados a um eletrômetro com um cabo e são fáceis de transportar. A precisão alcançada na prática clinica methor do que $\pm 5 \%(2 \sigma)$ é suficiente para o requisito da dosimetria in vivo (Rudén, 1975).

\subsection{Fundamentos Teóricos}

\subsubsection{Medida in vivo da dose de entrada}

Um dos objetivos da dosimetria in vivo é comparar as doses medidas a partir do sinal dos dosimetros colocados sobre a pele do paciente com os valores teóricos calculados pelo sistema de planejamento do tratamento. Entretanto, como a exatidão do cálculo da dose na pele é dificil, devido à falta de equilibrio eletrônico, o sinal do dosimetro é convertido em dose em um ponto próximo da pele, mas em uma certa profundidade onde a exatidão do sistema de planejamento do tratamento (TPS) é muito mais satisfatória. Um ponto está localizado próximo da superfície de entrada do feixe, na profundidade de dose máxima (a dose correspondente é chamada dose de entrada) e o outro ponto está localizado próximo da superfície de saída do feixe (a dose correspondente é dita dose de saida).

As medidas de dose de entrada servem, em geral, para verificar o rendimento e o desempenho do equipamento de tratamento, a exatidão do posicionamento do paciente, os 
parâmetros físicos da unidade de tratamento, a presença de filtros e outros modificadores do feixe, os erros de transferência de dados e o cálculo do número de unidades monitoras.

As medidas de dose de entrada podem ser realizadas durante cada sessão do tratamento para todos os pacientes com o propósito de detectar erros nas sessòes individuais de tratamento devido ao mau funcionamento do equipamento e às falhas humanas ou, ainda, os valores de dose de entrada (e saida) podem ser obtidos para todos os pacientes durante uma ou duas sessões do tratamento com o objetivo de detectar erros sistemáticos na liberação da dose durante os tratamentos individuais, que estão freqüentemente relacionados com erros na transferência da informação.

A dosimetria in vivo pode ser realizada em um número limitado de pacientes irradiados com técnicas padrões, com o objetivo de se avaliar a exatidão global na liberação da dose em um departamento, estimar e melhorar a exatidão no cálculo da dose e no fornecimento de técnicas de tratamento especificas, ou para verificação de técnicas de tratamento antes da sua implementação na rotina clínica. As medidas repetidas de dose in vivo em um número limitado de pacientes fornecem informações a respeito da influência da anatomia do paciente sobre a exatidão da dose liberada bem como sobre a reprodutibilidade do método de tratamento na prática diária.

\subsubsection{Dosimetria termoluminescente}

Determinados materiais, quando aquecidos e após serem expostos à radiação ionizante, podem emitir luz. Os materiais que apresentam essa propriedade são ditos termoluminescentes. A quantidade de luz emitida, proporcional à quantidade de radiação recebida, é mensurável, e o processo de quantificaçâo da dose de radiação é denominado dosimetria termoluminescente.

Os dosimetros termoluminescentes são constituídos de cristais e o fenômeno da termoluminescência pode ser explicado qualitativamente por meio de um modelo de bandas de energia. No interior de um cristal ideal existem três bandas distintas de energia (Fig. la). Uma banda de energia menor, denominada banda de valência, onde os elétrons permanecem em estados ligados de energia. Uma banda de energia maior, denominada banda de condução. representativa de todos os elétrons em estados não ligados de energia e, portanto, livres para 
migrarem através da rede cristalina. E uma banda intermediária, conhecida como a banda proibida. No caso de um cristal ideal nào condutor, à temperatura ambiente, a banda de valència se encontra repleta de elétrons e a banda de condução vazia. É altamente improvável para um elétron da banda de valència atravessar a banda proibida rumo à banda de condução, a menos que esteja sob a influência de forças externas.

No caso de um cristal real, existem imperfeições/defeitos na banda proibida que permitem aprisionar os elétrons da banda de condução, como ilustrado na Figura 1b. A presença dos defeitos em um material é importante para o fenômeno da termoluminescência.

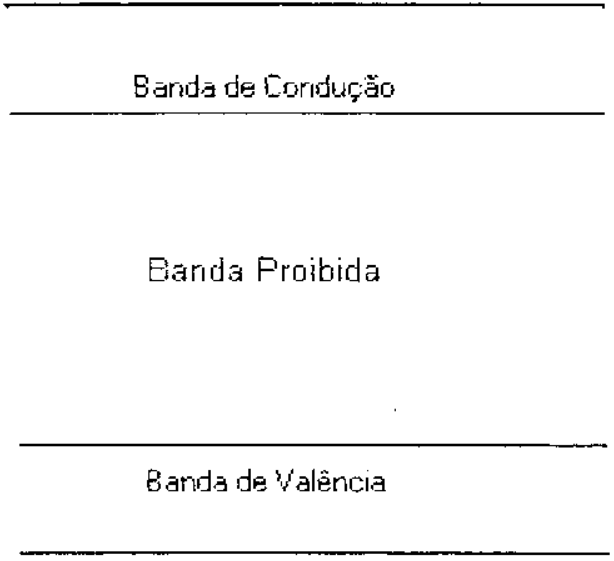

(a)

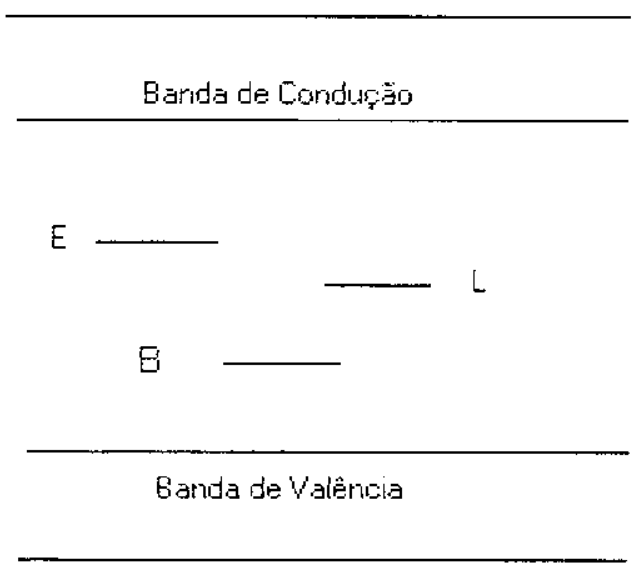

(b)

FIGURA 1 - Modelo de bandas de energia para um cristal ideal (a) e um cristal real (b). Fonte - Mackinlay, 1981

Na Figura 1b, o nivel de energia E (região com excesso de carga positiva) representa uma armadilha de elétron, $B$ (região com excesso de carga negativa) representa uma armadilha de buraco e L é um centro de luminescència, onde os elétrons e os buracos podem se recombinar emitindo fótons. O processo da termoluminescência observado em um material exposto à radiação ionizante pode ser dividido em dois estágios (Mackinlay, 1981): (i) ionização e aprisionamento do elétron, e (ii) recombinação de um elétron com um buraco com emissão de fótons. A Figura 2 ilustra a configuração da banda de energia para cada estágio. 


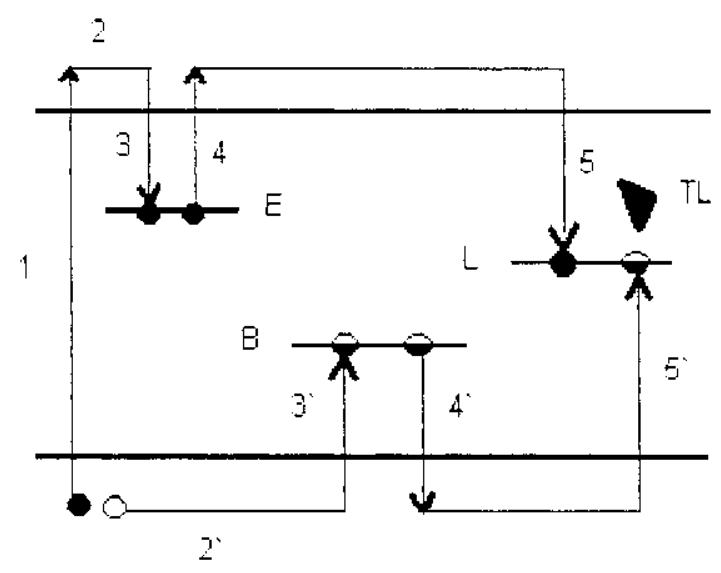

FIGURA 2 - Modelo de bandas de energia para a termoluminescència. Fonte - Mackinlay, 1981

O material termoluminescente (TL) absorve a radiação ionizante e, como efeito da interação da radiação com a matéria. são produzidos pares elétrons-buracos. Em termos do modelo de bandas, essa situaçào é equivalente à transferència dos elétrons da banda de valência para a banda de condução (passo 1). Esses elétrons encontram-se agora em estados não ligados de energia. podendo então se mover livremente no material (passo 2). Uma vez que as armadilhas de elétrons $\mathrm{E}$ estejam presentes, os elétrons podem ser aprisionados (passo 3). Os buracos positivos criados se comportam de maneira semelhante. Eles podem migrar pela banda de valència (passo 2') e podem ser aprisionados pelas armadilhas de buracos B (passo 3’).

Muitos dos centros de buracos apresentam instabilidade térmica e podem decair rapidamente à temperatura ambiente (passo 4'). Já os elétrons aprisionados permanecerão nessa condição até que recebam energia suficiente para escapar de suas armadilhas. A probabilidade disto ocorrer depende da profundidade da armadilha e da temperatura do material. O elétron pode adquirir suficiente energia térmica e ser libertado (passo 4). Os elétrons libertados, ao retornarem para o estado de menor energia na banda de valência, podem se recombinar com os buracos nos centros de luminescência $L$, e o excesso de energia é liberado como fótons com comprimento de onda visivel ou ultravioleta (passo 5). A quantidade de luz enitida depende da temperatura do material e do número de elétrons aprisionados e, portanto, da dose absorvida no cristal. 


\subsubsection{Dosímetros termoluminescentes}

Um dos materiais termoluminescentes mais utilizados para a dosimetria na radioterapia, e também um dos mais estudados, é o fluoreto de litio, dopado com magnésio e titânio (LiF:Mg,Ti) (Metcalfe et al., 1997, Mackinlay, 1981). O LiF:Mg, Ti foi desenvolvido pela Harshaw Chemical Company Inc., USA, em colaboração com Cameron (Horowitz, 1981). A Harshaw comercializa o fósforo de LiF conhecido como TLD-100 e seus variantes isotópicos TLD-600 e TLD-700. A TAB. 1 lista as proporções relativas de ${ }^{6} \mathrm{Li}$ e ${ }^{7} \mathrm{Li}$ contidas nesses fósforos. Na TAB. 2 são apresentadas as propriedades do TLD-100.

TABELA 1 - Constituição isotópica do TLD-100, 600 e 700 (Harshaw)

\begin{tabular}{ccc}
\hline Tipo do Fósforo & ${ }^{6} \mathrm{Li}(\%)$ & ${ }^{7} \mathrm{Li}(\%)$ \\
\hline TLD-100 & 7,5 & 92,5 \\
TLD-600 & 95,6 & 4,4 \\
TLD-700 & 0,01 & 99,99 \\
\hline Fonte - Mackinlay, 1981 & &
\end{tabular}

Fonte - Mackinlay, 1981

TABELA 2 - Propriedades do TLD-100

\begin{tabular}{lc}
\hline \multicolumn{1}{c}{ Propriedades } & LiF \\
\hline Material de dopagem & Mg. Ti \\
Número atômico efetivo (tecido 7,64$)$ & 8.2 \\
Densidade física $\left(\mathrm{g} \mathrm{cm}^{-3}\right)$ & 2.64 \\
Máximo comprimento de onda da luz emitida $(\mathrm{nm})$ & 400 \\
Decaimento do sinal TL do pico principal a $20^{\circ} \mathrm{C}$ & $<10 \%$ por ano \\
Supralinearidade $(\mathrm{Gy})$ & 1 \\
\hline
\end{tabular}

Fonte - Metcalfe ct al., 1997

A forma mais utilizada do TLD é a pastilha $\left(3,15 \times 3,15 \mathrm{~mm}^{2}\right.$ de área), disponivel com várias espessuras entre $0,14 \mathrm{~mm}$ a $0,9 \mathrm{~mm}$ (Kron et al., 1993c). 


\subsubsection{Características dosimétricas do LiF:Mg,Ti (TLD-100)}

\section{Curva de Emissão}

A curva de emissão termoluminescente representa a variação da intensidade do sinal TL em função da temperatura de aquecimento durante a leitura ou do tempo de aquisição. A FIG. 3 mostra a curva de emissão do LiF:Mg,Ti. Até uma temperatura de $250{ }^{\circ} \mathrm{C}$ podem ser observados seis diferentes picos de emissão, que estâo associados com armadilhas diferentes. Em dosimetria, normalmente se utilizam os denominados picos IV e V. A TAB. 3 apresenta os picos observados na FIG. 3, com as respectivas larguras dos intervalos de energia.

Os picos IV e V são os mais usados, geralmente, para a avaliação da leitura da dose no LiF:Mg,Ti. O pico V é o mais importante e é o denominado pico dosimétrico do material.

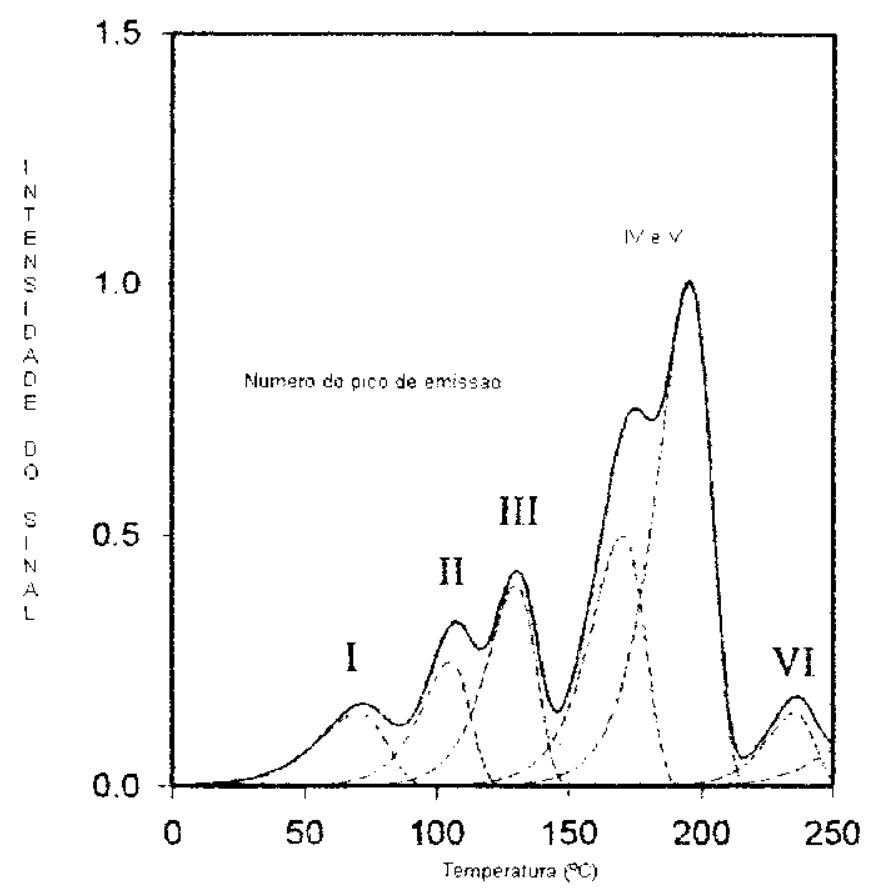

FIGURA 3 - Desenho esquemático da curva de emissão do LiF:Mg,Ti. O formato de cada pico de emissão foi calculado matematicamente. Fonte - Metcalfe et al., 1997 
TABELA 3 - Caracteristicas dos picos de emissão do LiF:Mg̣,Ti

\begin{tabular}{|c|c|c|c|c|}
\hline Pico $^{1}$ & $\begin{array}{l}\text { Diferenças } \\
\text { Energéticas } \\
\text { Aproximadas }\end{array}$ & $\begin{array}{l}\text { Temperatura de } \\
\text { Leitura }\left({ }^{\circ} \mathrm{C}\right)\end{array}$ & $\begin{array}{c}\text { Contribuição } \\
\text { Aproximada para a } \\
\text { Leitura }^{2}\end{array}$ & $\begin{array}{c}\text { Meia-Vida à } \\
\text { Temperatura } \\
\text { Ambiente }\end{array}$ \\
\hline I & 1,04 & 70 & 0 & $10 \mathrm{~min}$ \\
\hline II & 1,07 & 105 & 0,2 & $20 \mathrm{~h}$ \\
\hline III & 1,05 & 130 & 0,3 & 6 meses \\
\hline IV & 1,53 & 170 & 0,5 & 10 anos \\
\hline V & 2,21 & 195 & 1 & 80 anos \\
\hline $\mathrm{VI}$ & 1,70 & 235 & 0,1 & $>100$ anos \\
\hline
\end{tabular}

\section{Decaimento do Sinal TL}

O decaimento do sinal TL é o processo no qual o sinal termoluminescente sofre uma redução devido à liberação espontànea dos elétrons das suas armadihas com a conseqüente emissão de luz. Quanto menor o intervalo de energia entre a banda de condução e a armadilha, maior a probabilidade da enissão espontānea.

O sinal TL pode sofrer uma diminuição considerável dependendo do tempo transcorrido entre a irradiação e a leitura. Quando este tempo for grande. um fator de correção deve ser aplicado, sendo que o LiF apresenta decaimento térmico do sinal TL de 5 a $10 \%$ por ano. Um tratamento térmico pré-leitura apropriado possibilita a eliminação de parte do sinal que apresenta um importante decaimento do sinal TL térmico.

Zimmerman et al. (1966) verificaram que os vários picos na curva de emissão do LiF:Mg,Ti decaem, à temperatura ambiente, com meias-vidas no intervalo de poucos minutos a vários anos (TAB. 3). Como esperado, as meias-vidas aumentam com o aumento do intervalo de energia (aumentando-se a temperatura de leitura).

Os picos com meias-vidas longas são os mais estáveis e, conseqüentemente, os mais adequados para a dosimetria de radiação. Enquanto que os picos com meias-vidas curtas são 
sinais indesejáveis, os quais podem ser eliminados por meio de várias técnicas de tratamentos térmicos pré e pós-irradiação.

\section{Variação do sinal TL com a dose}

A FIG. 4 mostra a variação da resposta termoluminescente com a dose absorvida. Nessa figura, podem ser distinguidas quatro regiòes: entre os pontos A e B, existe um limite de deteç̧ão do sinal TL; entre B e C, a resposta TL tem comportamento linear com a dose dada e. por isso. é a regiào mais utilizada para medidas dosimétricas; entre os pontos $\mathrm{C}$ e $\mathrm{D}$ as leituras TL estão superestimando a dose dada, devido ao aumento da sensibilidade dos detectores (região de supralinearidade); após o ponto $\mathrm{D}$, observa-se uma diminuição da sensibilidade devido aos danos das radiaçòes provocados no detector.

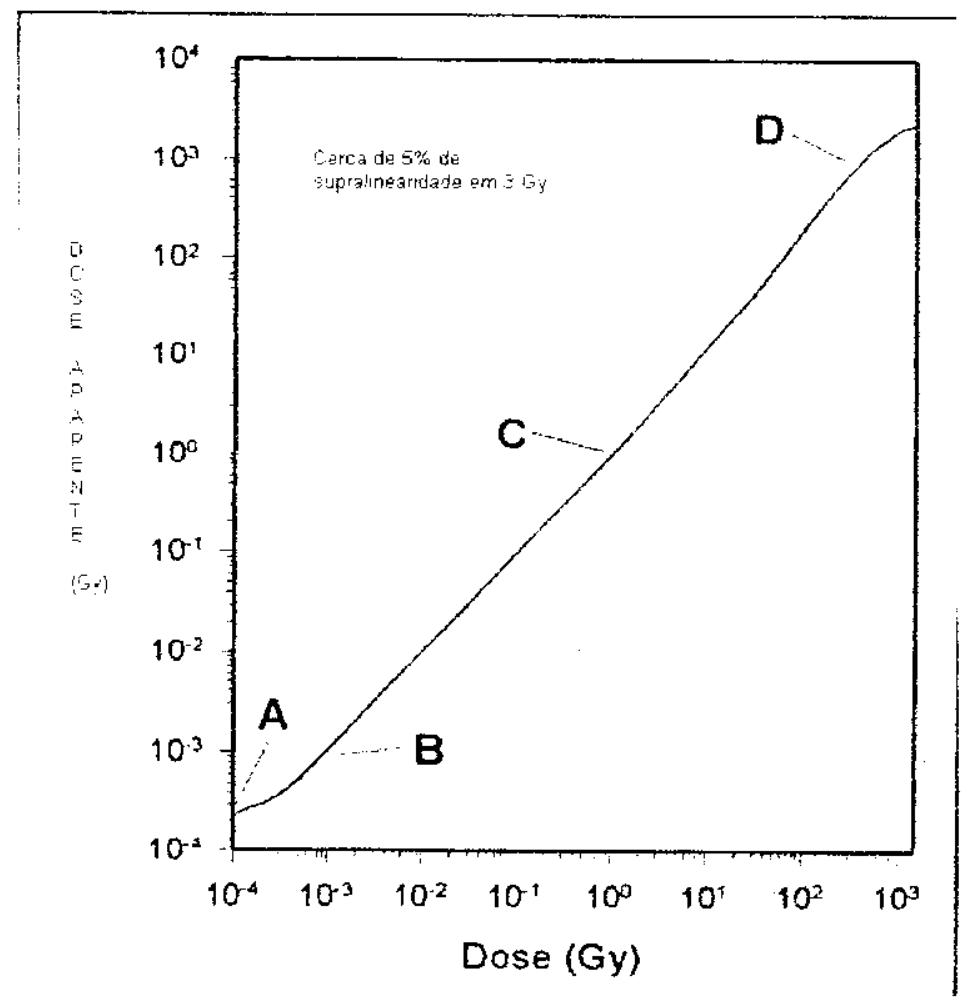

FIGURA 4 - Comportamento da resposta TL do LiF:Mg,Ti em função da dose. Fonte - Metcalfe et al., 1997 
O LiF:Mg,Ti permite medir doses no intervalo aproximado de $50 \mu \mathrm{Gy}$ até $100 \mathrm{~Gy}$. Para doses absorvidas relativamente baixas, a resposta TL é linear (5 x $10^{-5}$ a 1 Gy); acima da região linear de dose, a resposta se torna supralinear, saturando em uma dose de $10^{3} \mathrm{~Gy}$. $\mathrm{Na}$ prática. é recomendado usar o TLD na região linear.

\section{Supralinearidade}

O comportamento supralinear do LiF:Mg, Ti depende da composição química do material. Para a prática da dosimetria termoluminescente é importante observar que a supralinearidade pode ser influenciada pelo pico de emissão avaliado. Os vários picos na curva de emissão podem exibir comportamento supralinear diferente. O histórico de tratamento térmico tem importante influência sobre a supralinearidade. As temperaturas de aquecimento $\mathrm{e}$ a taxa de resfriamento alteram a supralinearidade no LiF.

No caso de se utilizar o dosímetro na regiào de supralinearidade. o sinal deve ser corrigido por meio de uma curva de calibração estabelecida com o TLD e a leitora termoluminescente respectiva. Essa curva deve ser verificada periodicamente.

\section{Sensibilidade}

A sensibilidade do LiF:Mg,Ti depende da composição do material e do histórico de tratamento térmico. Uma influência muito importante sobre a sensibilidade é a taxa de aquecimento durante a leitura e a taxa de resfriamento após o tratamento térmico à alta temperatura. A sensibilidade das pastilhas diminui com o tempo e com o uso. Há uma perda de cerca de 1,5\% por 10 Gy de dose absorvida (Horowitz 1993, Kron et al. 1993).

Existem dois métodos aproximados que garantem uma incerteza no fator de sensibilidade tão baixa quanto possivel: irradiar e determinar o fator para cada dosímetro ou; separar em lotes vários dosimetros com semelhantes sensibilidades e aplicar um fator de sensibilidade médio ao conjunto (Van Dam e Marinello, 1994).

O primeiro método consiste em se irradiar todos os dosimetros nas mesmas condições geométricas, fazer a leitura dos sinais e atribuir um fator de sensibilidade $S_{i}$ para cada um dos dosimetros dado por: 


$$
S_{i}=\frac{L_{i}}{L}
$$

Onde $L_{i}$ é a leitura TL do dosimetro de número i e $L$ é a média de todos os valores de $\mathrm{L}_{\mathrm{i}}$. Este fator de sensibilidade expressa a variação da resposta de cada dosimetro individualmente ao redor da média. Embora essa média possa variar a cada irradiação. $S_{i}$ deve permanecer constante, pois todos os dosímetros estão sujeitos às mesmas variações.

O segundo método consiste em separar os dosimetros TL em grupos de acordo com as sensibilidades apresentadas sem identificá-los individualmente (por exemplo, grupos de dosimetros com uma variação na resposta em relação à média do grupo menor que $\pm 1 \%$ ou $\pm 2 \%$ ) e aumentar o número de dosimetros usados para cada ponto de medida.

Os fatores de sensibilidade devem ser verificados periodicamente em ambos os métodos.

\section{Dependência Energética}

Para que se possa verificar as doses absorvidas no paciente, é essencial conhecer a dependência da resposta dos dosímetros TL com as várias energias de fótons e elétrons utilizadas. Essa dependencia é definida como uma medida da energia absorvida pelo dosimetro TL em comparação com a energia absorvida por um material de referenncia, quando submetido às mesmas condições de exposição à radiação.

O método de calibração do dosimetro mais confiável consiste em se comparar diretamente a resposta do dosímetro TL e a capa de equilibrio eletrònico associada com a resposta de uma câmara de ionização calibrada, ambos irradiados no mesmo feixe usado nos tratamentos, nas condições experimentais mostradas na FIG. 6.

\section{Tratamento Térmico}

A finalidade do tratamento térmico é restabelecer o material TL a sua condição existente antes da exposição à radiação ionizante, esvaziando completamente e estabilizando as armadilhas do material após a sua avaliação. O procedimento escolhido para o tratamento 
térmico influi drasticamente na estrutura da curva de emissão TL. Um forno dedicado é parte fundamental na dosimetria TL. ele deve ser capaz de manter a temperatura pré-estabelecida dentro de um intervalo bem especificado. Entretanto, a reprodutibilidade de um ciclo de aquecimento é mais importante que a exatidão absoluta das temperaturas alcançadas. Isto inclui a taxa de aquecimento e, principalmente, a taxa de resfriamento.

Cameron et al. (1968) e Zimmerman et al. (1966) propuseram um procedimento padrão de tratamento térmico pré-irradiação. Tal procedimento consiste em tratar os TLDs a $400{ }^{\circ} \mathrm{C}$ por $1 \mathrm{~h}$ (tratamento térmico de alta temperatura), para desexcitar todas as armadilhas presentes no material TL; seguido por outro tratamento a $80^{\circ} \mathrm{C}$ por $24 \mathrm{~h}$ (tratamento térmico de baixa temperatura) que, como demonstrou Zimmerman et al. (1966). elimina quase que completamente os dois primeiros picos de meias-vidas curtas, e reduz a influência do terceiro pico.

Booth et al. (1972) sugeriram que os TLDs fossem tratados termicamente por $1 \mathrm{~h}$ a $400^{\circ} \mathrm{C}$ antes de irradiá-los e por $10-15 \mathrm{~min}$ a $100{ }^{\circ} \mathrm{C}$ após a irradiação ou antes da leitura, tendo este último procedimento propósito similar ao tratamento térmico de baixa temperatura acima mencionado. Mackinlay (1981) sugere um tratamento térmico de baixa temperatura de $1-2$ h a $100^{\circ} \mathrm{C}$ ou $16-24$ h a $80^{\circ} \mathrm{C}$.

\section{Calibração}

O método de calibração usado depende da forma do dosimetro e da exatidão exigida. Os dosímetros são divididos em grupos de calibração. O número máximo de dosímetros em um grupo é limitado pela estabilidade da leitora e pela necessidade de assegurar que todo o grupo é submetido a um idèntico tratamento térmico. Cada grupo novo deve ser irradiado e tratado uma ou duas vezes antes de se obter resultados confiáveis (não é necessário que o grupo receba a mesma dose). Após a pré-irradiação inicial, devem ser realizadas três irradiações, no mínimo, fornecendo-se a mesma dose a todos os dosimetros. O desvio das leituras de cada dosimetro em relação à média do grupo e a variação das leituras individuais dos dosímetros são então calculados. 


\section{Armazenamento e manuseio}

Recomenda-se evitar a exposição do material TL à luz ultravioleta e armazená-lo no escuro, pois a radiação UV pode aumentar o sinal de fundo e o decaimento do sinal TL. Entretanto. esses efeitos não representam um problema para o uso do fluoreto de lítio em doses terapèuticas.

$\mathrm{O}$ dosímetro TL não deve ser manuseado, de modo que não sofra contaminaçào. especialmente com gordura. O melhor método para se manusear pastilhas é utilizar pinça a vácuo. Caso as pastilhas sofram contaminação, devem ser lavadas com metanol puro e enxaguadas com água deionizada.

\section{Controle de qualidade}

Mayles et al (1999) sugerem, como controle de qualidade do sistema TLD, uma lista de verificações que devem ser realizadas regularmente (TAB. 4).

TABELA 4 - Verificações regulares no sistema TLD

\begin{tabular}{|c|c|c|}
\hline Verificação & Freqüência & Notas \\
\hline Desvio padrào & Todo tratamento térmico & $\begin{array}{l}\text { Com relação às pastilhas de } \\
\text { calibração }\end{array}$ \\
\hline Curvas de emissão & Mensalmente & $\begin{array}{l}\text { Comparar com curva de } \\
\text { referência }\end{array}$ \\
\hline Limpeza da prancheta & Diariamente & \\
\hline Luz interna de referência & Diariamente & Estabilidade dentro de $2 \%$ \\
\hline Sinal de fundo sem pastilla & Diariamente & Antes do uso \\
\hline $\begin{array}{l}\text { Sinal de fundo com pastilha } \\
\text { não irradiada }\end{array}$ & Mensalmente & \\
\hline Temperatura do forno & Na aceitação & E na suspeita de problemas \\
\hline $\begin{array}{l}\text { Estabilidade do grupo de } \\
\text { controle }\end{array}$ & Todo tratamento térmico & Estabilidade dentro de $2 \%$ \\
\hline Luz externa de referencia & 3 meses & $\begin{array}{l}\text { Não é possivel para todas as } \\
\text { leitoras }\end{array}$ \\
\hline
\end{tabular}




\subsection{Revisão bibliográfica}

Essers e Mijnheer (1999) fizeram uma revisão da prática corrente da verificação da dose liberada ao paciente, onde avaliaram os vários métodos e filosofias aplicadas: a medida de cada campo para cada fração de cada paciente e um número limitado de verificações para todos os pacientes.

Apresentaram a experiência de vários centros, fornecendo informações sobre os vários tipos de erros detectados pela dosimetria in vivo, incluindo sua freqüência e magnitude:

- Medidas de dose de entrada durante cada sessão de tratamento para todos os pacientes um estudo com 43 pacientes (1918 sessões) tratados com fótons de alta energia (Nilsson et al., 1988 ) mostrou a presença de um desvio, entre a dose medida e a dose prescrita, maior que $4 \%$ em $14 \%$ das sessões. Os autores apontam algumas razões para o desvio, tais como erros no ajuste do número de unidades monitoras, distância, tamanho de campo, ou energia do feixe, que podem ocorrer em aceleradores antigos que não possuem um sistema de verificação.

- Medidas de dose de entrada (e saida) para todos os pacientes durante uma ou duas sessòes do tratamento - o estudo de Leunens et al. (1992) mostrou que a transferència errônea de dados como, por exemplo, durante a preparação do plano de tratamento, pode levar a uma sub-dosagem ou sobre-dosagem de mais de $5 \%$ para $5 \%$ dos casos, e esses erros poderiam ter sido rastreados por meio da dosimetria in vivo em $96 \%$ dos casos.

- Dosimetria in vivo para um número limitado de pacientes irradiados com técnicas padrões - no hospital universitário St. Rafael em Leuven, um dos primeiros hospitais a estabelecer tal programa de dosimetria in vivo, foram rastreados vários erros de transferências de dados no processo de planejamento do tratamento. Em Leuven e em um hospital em Villejuif, um estudo durante irradiação de campo "mantle" mostrou que, para $34 \%$ dos casos, ocorreram erros no "setup" dos blocos de blindagem. Em Villejuif, para 22\% dos "setups", resultou um erro no fornecimento da dose de mais de $5 \%$

Com base nos resultados dos diversos estudos pôde-se concluir que nos centros que dispunham de equipamentos modernos com sistemas de verificação bem como de programas de controle de qualidade, ainda se constatava um erro sistemático maior que $5 \%$ na liberação da dose para $0,5-1 \%$ dos tratamentos dos pacientes. Os autores concluíram que a verificação da dose do paciente deveria ser uma parte essencial de um programa de controle de qualidade 
em um departamento de radioterapia e. como a comunidade da radioterapia está fazendo a transição de terapias convencionais 2D para 3D e para terapia com feixe de intensidade modulada, IMRT, recomendam que cada nova técnica de tratamento seja verificada sistematicamente para alguns pacientes, e realizar a dosimetria in vivo algumas vezes para cada paciente para situações onde se pode minimizar os erros na administração da dose.

Huyskens et al. (2001) relataram a implantação da dosimetria de entrada in vivo em grande escala em um centro de radioterapia. A medida da dose no paciente é realizada no inicio do tratamento, nas primeiras três frações, de modo a tornar possivel corrigir quaisquer erros detectados. As medidas in vivo são realizadas com diferentes tipos de diodos, o que permite avaliar flutuações estatisticas devido às várias características dos diodos. Foram aplicados fatores de correção para tamanho de campo e variações na resposta em diferentes distâncias fonte-superfície (DFS) no intervalo de energia de 8 a $18 \mathrm{MV}$. A dependència com a temperatura foi considerada no procedimento de calibração. Foram utilizados diodos de forma cilíndrica em campos de tratamento tangenciais, conseqüentemente, não foram necessárias correções para dependència direcional. Os niveis de tolerância e niveis de ação estabelecidos para diferentes locais de tratamento estão listados na TAB. 5.

TABELA 5 - Niveis de ação e tolerância estabelecidos para diferentes regiōes de tratamento

\begin{tabular}{ccc}
\hline Local do Tratamento & Técnica de Tratamento & Nivel de Tolerância \\
\hline Mama (ressecção & Campos tangenciais, 6-8 MV, 1/2 campo & $\pm 8 \%$ \\
parcial) & bloqueado, filtro dinâmico & \\
Mama (mastectomia) & Campo anterior, 6-18 MV, 3/4 campo bloqueado & $\pm 8 \%$ \\
Cabeça \& Pescoço & Técnica de campo individual para cada & $\pm 8 \%$ \\
& paciente, 4-6 MV, 1/2 campo bloqueado, filtro & \\
Tórax/Pelve & compensador/ filtro dinâmico & $\pm 5 \%$ \\
& Técnica de campo individual para cada & \\
\hline
\end{tabular}

Os resultados da dosimetria mostraram que o posicionamento do diodo se torna mais critico em campos de tratamento que incorporam filtros ou filtros compensadores, reduzindo a precisão no processo de controle de qualidade. Em tratamentos simples, planejados 
manualmente, o nivel de complexidade é baixo (sem filtros, compensadores ou campos assimétricos). Conseqüentemente, as variações dos valores esperados são pequenas; para energias entre 6-8 MV, foi calculado um desvio padrão de $2,3 \%$ (1 $\sigma)$ e 2,2\% para $18 \mathrm{MV}$. Em tratamentos planejados no computador, para energias entre 6-8 MV, o valor calculado foi de $2,7 \%$. O maior desvio foi registrado na técnica de tratamento tangencial, com um desvio padrão de aproximadamente $5 \%$. As medidas em pacientes mastectomizadas mostraram um deslocamento significativo no sentido de variaçòes positivas, sugestionando um erro sistemático. A distribuição apresentou uma média de 3,5\% com um desvio padrão de $3,1 \%$.

O estudo realizado por Viegas (2003) demonstrou a viabilidade da implantação de uma rotina de dosimetria in vivo com uso de TLDs, no tratamento de câncer de cabeça e pescoço. Após a caracterização dos dosímetros. um tratamento de câncer de cabeça e pescoço foi simulado em objeto simulador antropomórfico. de modo a testar o sistema dosimétrico. Os valores de dose de entrada medidos apresentaram uma variação de $\pm 5 \%$ com relação à dose determinada por meio do planejamento. Nas doses medidas diretamente no paciente, observou-se uma tendência da resposta TL em superestimar as doses de entrada, principalmente para os campos de fossa supraclavicular (FSC), embora estivessem dentro de um intervalo aceitável de $\pm 5 \%$.

Banjade et al. (2003) realizaram medidas de dose de entrada in vivo usando dosimetros termoluminescentes de LiF:Mg:Ti sem capa de equilibrio eletrônico. Os TLDs foram calibrados em um objeto simulador de água "sólida", em função da dose na profundidade de dose máxima $\left(\mathrm{d}_{\text {max }}\right)$. Os TLDs foram colocados na superficie do objeto simulador e uma câmara de ionização foi posicionada a $5 \mathrm{~cm}$ de profundidade para um feixe de $6 \mathrm{MV}$. Os TLDs foram expostos a uma dose de 1 Gy na profundidade de dose máxima $\left(\mathrm{d}_{\text {max }}\right)$ como determinado pela câmara de ionização. Os dosímetros TLs calibrados foram utilizados para medir a dose de entrada durante o tratamento dos pacientes e, simultaneamente, no objeto simulador para verificação da estabilidade do sistema. A dose medida no objeto simulador mostrou-se próxima à dose determinada por meio do sistema de planejamento do tratamento, sendo as discrepâncias menores que 4,1\% (média 1,3\%).

A dose de entrada medida durante os tratamentos dos pacientes mostrou-se compativel com a dose determinada por meio do TPS, com uma discrepância máxima de 5,7\% (média 2,2\%). Com relação à exatidão das medidas, os autores citam trabalhos da literatura (Kron, 
1993a) que sugerem que, usando-se 2 dosímetros por ponto de medida e 4 como dosímetros padrão, é possivel alcançar uma exatidão melhor que 5\%. Ainda, sugerem que a exatidão tipica atingida com TLDs na prática clinica está entre $\pm 3 \% \mathrm{e} \pm 5 \%$, o que atende às exigèncias da dosimetria in vivo. Os resultados alcançados por Banjade et al. (2003) foram considerados dentro do erro estimado de $\pm 3 \%$ a $\pm 5 \%$. Concluiram, então, que a técnica empregada de medida de dose de entrada usando TLD sem capa de equilibrio eletrônico forneceram resultados dentro dos limites aceitáveis de incerteza para as medidas $\mathrm{TL}$, bem como para os procedimentos de verifícação de dose na rotina clínica.

Herbert et al. (2003) conduziram um estudo para avaliar a utilidade clinica da dosimetria in vivo. Foram utilizados diodos (calibrados para condições típicas de tratamento) para medidas de dose de entrada em 62 pacientes representando uma variedade de regiões de tratamento. As medidas foram comparadas com os valores calculados pelo sistema de planejamento, com os resultados encontrados dentro dos niveis de tolerância na maioria das regiões de tratamento. As maiores discrepâncias foram encontradas em medidas realizadas no tratamento de mama (até 16\% para campos tangenciais). Essa discrepância é devida ao uso de filtros para a maioria dos campos de tratamento e a não uniformidade dos contornos do paciente. Foi examinada a sensibilidade da dose de entrada registrada com relação a erros de posicionamento do diodo. Os resultados do estudo indicaram a importância de separar os dois tipos de erros: erros relacionados com a técnica de medida e erros relacionados com o "setup".

Em um estudo de Swinnen et al. (2004). foi realizada a medida in vivo de dose de entrada com TLDs na forma de pó, com o objetivo de se avaliar a exatidão global do tratamento do paciente, comparando-se as doses fornecidas aos pacientes com as doses calculadas pelo sistema de planejamento do tratamento em diferentes instituições. Foram construidas e testadas capas cilindricas de equilibrio eletrônico de cobre para os TLDs, irradiados em feixe de fótons de $6 \mathrm{MV}$. Os dosimetros com as capas de equilibrio eletrônico foram calibrados para medir dose de entrada e a perturbação da dose abaixo dos mesmos foi avaliada. Durante as medidas in vivo, para cada paciente, dois TLDs foram irradiados com a capa de equilibrio eletrônico colocados no eixo central do feixe em dois dias consecutivos, de modo a verificar a reprodutibilidade das respostas. A média das duas medidas foi usada para a determinação da dose de entrada. A razão média das doses medidas e calculadas foi igual a 
$0,986 \pm 0,017(1 \sigma)$. As duas leituras TLs por paciente foram todas reprodutíveis dentro de $2 \%$.

\subsubsection{Protocolos ESTRO "booklet" nr. 1 e "booklet" nr. 5}

O objetivo do booklet nr. 5 é fornecer à comunidade radioterapeuta um guia prático para a implementação, na rotina clínica, da dosimetria de entrada in vivo com diodos em feixes de fótons. Esse guia representa um complemento do booklet $\mathrm{nr} .1$ "Methods for in vivo dosimetry in external radiotherapy" (Van Dam e Marinello, 1994), que aborda questões mais filosóficas relacionadas ao uso da dosimetria in vivo.

\subsubsection{Dose de entrada}

A dose de entrada $D_{\text {entrada }}$ é definida em um ponto a uma certa distância da superficie do paciente, na entrada do feixe (conhecida como "superfície de entrada"). Essa distância é igual à profundidade de máxima dose, $\mathrm{d}_{\max }$ (FIG. 5).

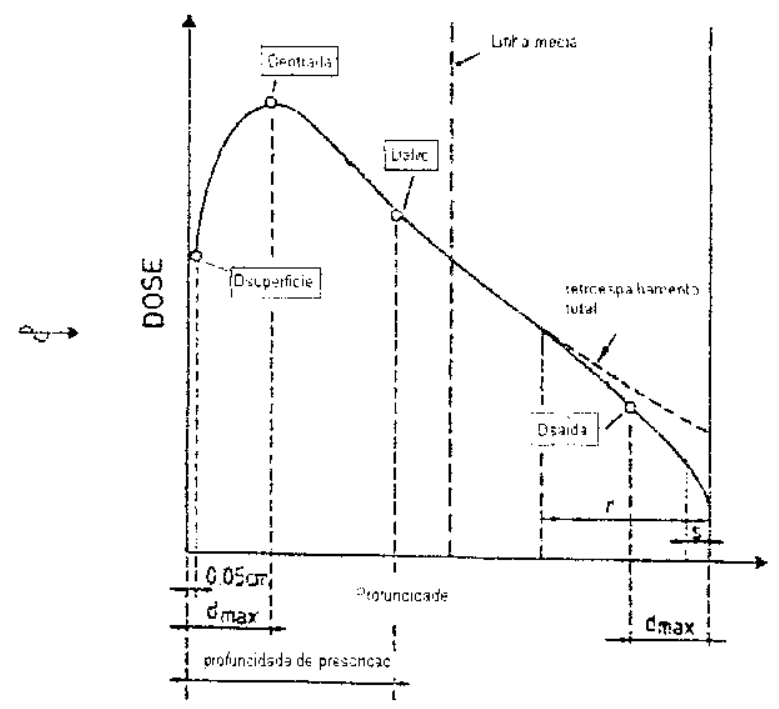

FIGURA 5 - Representação esquemática das diferentes doses envolvidas na dosimetria in vivo para aplicação de um único feixe de fótons. Fonte - Van Dam e Marinello, 1994 


\subsubsection{Dosímetros termoluminescentes}

$\mathrm{O}$ sinal TL é influenciado tanto por parâmetros físicos quanto por parâmetros geométricos. As diferentes influências são consideradas na calibração dos dosimetros e na determinação dos fatores de correção (ver seçòes 1.3.1.4 e 1.3.1.5).

Os paràmetros físicos (relacionados com as propriedades do material do dosímetro) que podem influenciar a resposta TL e, portanto, devem ser considerados são:

- Variação da resposta TL com a dose.

- Dose acumulada: a sensibilidade do TLD de LiF apresenta dependencia crítica com relação aos tratamentos térmicos realizados antes da primeira irradiação e após o uso do dosimetro; o tratamento térmico quando não realizado corretamente pode alterar as propriedades dosimétricas do material TL.

- Taxa de dose: o LiF é independente da taxa de dose de até 45 Gy por pulso de $0,1 \mu$ s. Portanto, não é necessária qualquer correção para taxa de dose aplicada no uso clínico;

- Decaimento do sinal TL.

- Temperatura: a resposta TL é independente das variaçòes de temperatura para aplicação na dosimetria in vivo, pois as temperaturas necessárias para produzir a emissão de luz no cristal TL são altas comparadas com a temperatura da sala ou do paciente;

- Energia do feixe.

- Direção do feixe: a resposta intrínseca do dosímetro TL não é influenciada pelo feixe. Portanto, não é necessária qualquer correção, exceto se a capa de equilibrio eletrônico associada tiver uma forma assimétrica.

Os parâmetros geométricos estão relacionados com o material do dosimetro, com a metodologia de medida e com o formato/espessura da capa de equilibrio eletrônico do dosímetro. Como as medidas de dose de entrada são realizadas com o TLD colocado do lado de fora do paciente, as condições de espalhamento do fótons experimentadas pelo dosímetro TL são diferentes daquelas no ponto de definição de dose de entrada, ou seja, no ponto de dose máxima dentro do paciente. Ainda, o dosimetro $\mathrm{TL}$ pode receber diferentes quantidades de elétrons espalhados pelo cabeçote do acelerador. Conseqüentemente. o efeito do tamanho de campo, distância fonte-superficie (DFS), e presença de modificadores do feixe sobre a 
contribuição da contaminação dos elétrons espalhados podem originar consideráveis variaçòes nos fatores de correçào.

\subsubsection{Capa de equilíbrio eletrônico}

A medida da dose de entrada, para que seja reprodutivel, deve ser realizada com uma quantidade suficiente de material (capa de equilibrio eletrônico) em frente e ao redor do dosimetro colocado na superficie da pele. O problema é que com o aumento da energia do feixe de tratamento, maior é a espessura da capa de equilibrio eletrônico necessária, o que pode levar a uma sub-dosagem do volume de tratamento, junto com uma perda do efeito de poupar a pele.

Um modo de reduzir as dimensões da capa de equilibrio eletrônico é utilizar um material com alta densidade. Porém, neste caso, essa nova capa pode alterar a resposta do dosimetro (mantidas as mesmas condiçòes de irradiação). A calibração do dosimetro deve, então, ser realizada junto com a capa.

O formato da capa de equilibrio eletrônico influencia a resposta angular: capas cilíndricas e semi-esféricas apresentam diferentes dependèncias angulares. A espessura da capa determina as condições de espalhamento no dosimetro. Para minimizar os fatores de correção e garantir uma maior exatidão nas medidas, è recomendável utilizar uma capa com uma espessura igual à profundidade de dose máxima, que equivale à profundidade de equilibrio de particulas carregadas.

No caso de se utilizar o dosímetro sem a capa de equilíbrio eletrônico, é necessário estabelecer fatores de correção em um objeto simulador nas mesmas condições de irradiação do paciente. Estes fatores dependem da geometria de irradiaçào (tamanho de campo. DFS, etc) e da presença ou não de acessórios no cabeçote da unidade de tratamento.

\subsubsection{Calibração dos dosímetros termoluminescentes}

$O$ fator de calibração de dose de entrada, $F_{\text {caul }}^{\text {entrata }}$, é definido (sob condições de referência) como sendo o fator pelo qual o sinal $L_{\text {entrada }}$ do dosímetro, posicionado sobre a pele 
do paciente na superficie de entrada com a capa de equilibrio eletrônico, deve ser multiplicado para produzir a dose de entrada $D_{\text {cntrada. }}$

$$
F_{c a l}^{\text {cntrada }}=\frac{D_{\text {entruda }}}{L_{\text {entrada }}}
$$

O fator $F_{c a l}^{e r t r a d a}$ é determinado colocando-se o dosimetro sobre a superficie de um objeto simulador geométrico homogêneo, no lado de incidencia do feixe. e sua resposta é comparada com a resposta fomecida por uma câmara de ionização calibrada, posicionada em $\mathrm{d}_{\max }$ (FIG. 6).

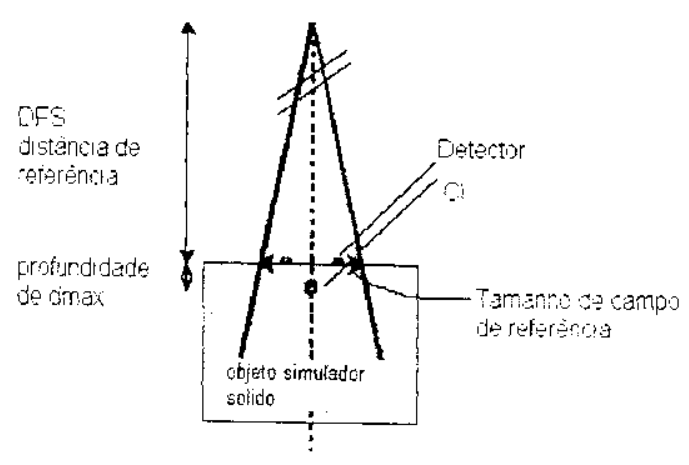

FIGURA 6 - Representação esquemática para determinação do fator de calibração de dose de entrada de um dosimetro. Fonte - Huyskens et al., 2001

\subsubsection{Determinação dos Fatores de Correção}

Após a determinação do fator de calibração, deve ser estabelecido um conjunto de fatores de correção que levam em conta as variações na resposta do dosimetro, em situaçòes que diferem das condições de referência. Esses fatores que influenciam a resposta do dosimetro são: tamanho do campo, DFS, presença de modificadores do feixe como filtros físicos, presença de bandeja e blocos a o ângulo de incidència do feixe (Eq. 3).

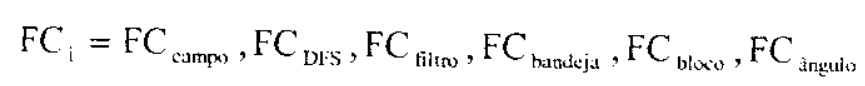


Onde $\mathrm{FC}_{\text {campo }}, \mathrm{FC}_{\mathrm{DFS}}, \mathrm{FC}_{\text {filtro, }} \mathrm{FC}_{\text {banduja }}, \mathrm{FC}_{\text {blowo }}$ e $\mathrm{FC}_{\text {angulo }}$ representam os fatores campo, distância fonte-superficie, filtro, bandeja, bloco $e$ ângulo de incidència do feixe. respectivamente.

Os fatores de correção são determinados como a razão da leitura de uma câmara de ionização $\left(\mathrm{L}_{\mathrm{CI}}\right)$ e o sinal do dosímetro $\mathrm{TL}\left(\mathrm{L}_{\mathrm{TLD}}\right)$ para uma situação clinica de irradiação normalizada para a mesma razão para a situação de referència.

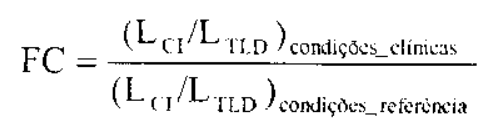

- Fatores de correção para tamanho do campo são medidos para campos quadrados no intervalo entre $5 \times 5 \mathrm{~cm}^{2}$ a $40 \times 40 \mathrm{~cm}^{2}$, em uma DFS de referência de $100 \mathrm{~cm}$.

- Fatores de correção para DFS devem ser medidos dentro de um intervalo determinado pelas condições clínicas, por exemplo, de 75 a $110 \mathrm{~cm}$, no campo de referência de $10 \times 10 \mathrm{~cm}^{2}$.

- Fatores de correção para o ângulo do filtro físico podem depender do tamanho de campo. Săo medidos na DFS de referência, para diferentes tamanhos de campos; e determinados como a razão do sinal da câmara de ionização e do dosímetro termoluminescente. A razão do sinal da câmara de ionização e do TLD é, nesse caso, normalizada para a mesma razão para o campo aberto (com o mesmo tamanho de campo).

- Os fatores de correção para bandeja podem depender da DFS e do tamanho de campo. Podem ser determinados repetindo todas as medidas realizadas para fatores de correção para DFS e tamanho de campo, e normalizados para a condição de referència com o campo aberto.

- A influência do ângulo de incidência do feixe na resposta do dosimetro é medida para diferentes ângulos do sistema funcional de suporte ("gantry") e da mesa de tratamento, e normalizada para a condição de referência com o eixo central do campo coincidindo com o eixo de simetria.

- Fatores de correção para bloco podem ser medidos para diferentes blocos definindo campos quadrados a uma abertura fixa do colimador (por exemplo, uma abertura de 
$20 \times 20 \mathrm{~cm}^{2}$ para blocos definindo campos de $5 \times 5,10 \times 10$ e $\left.15 \times 15 \mathrm{~cm}^{2}\right)$. A condição de referência é o campo aberto correspondente (com a mesma abertura do colimador).

Para evitar o uso redundante dos fatores de correção, pode-se empregar valores mínimos de fatores abaixo dos quais podem ser ignorados (por exemplo, se um fator de correção apresenta um desvio menor que $1 \%$ com relação ao valor unitário, a correção está dentro da incerteza da medida). Na prática, considera-se que todos os fatores de correção são independentes e verifica-se a exatidão da dose medida quando mais de um parâmetro (por exemplo, tamanho de campo, DFS e filtro) são modificados da condição de referencia ao mesmo tempo.

\subsubsection{Cálculo da Dose Absorvida}

Nas condições de referência, a dose de entrada medida é dada por:

$$
\left(D_{\text {entrada }}\right)_{q}=\left(F_{\text {cal }}^{\text {enrada }} \times \operatorname{SinalTL}\right)_{q}
$$

Onde $q$ é a qualidade do feixe aplicado.

Para as diferentes condições de tratamento encontradas na prática clínica, a dose de entrada medida é calculada multiplicando-se a Eq. 5 pelos fatores de correção apropriados.

$$
\left(\mathrm{D}_{\text {entrada }}\right)_{q}=\left(\mathrm{F}_{\text {cal }}^{\mathrm{cntrada}} \times \operatorname{SinalTL} \times \prod F C\right)_{q}
$$

Na Eq. 6, ПFC é o fator de correção total para linearidade, decaimento do sinal TL, tamanho de campo, orientação, presença de modificadores do feixe, distância foco-superficie. 


\subsubsection{Interpretação da medida}

\section{Nivel de tolerância e nível de ação}

Os niveis de tolerância e de ação determinam na prática o número de "erros" detectados. Caso o nível de tolerância estipulado seja muito pequeno, um número muito grande de medidas terá que ser repetido. De forma contrária, se o nível de tolerância for muito grande, erros na administração da dose de tratamento não serão detectados.

No caso de se empregar a dosimetria in vivo para verificar determinados tratamentos, os valores dos niveis de tolerância e ação podem variar de acordo com o tipo de tratamento. Tratamentos que envolvem alta dose e alta precisão requerem niveis estreitos de tolerância. A determinação do valor real do nivel é baseada em diferentes fatores:

- $\quad \mathrm{Na}$ incerteza do método de medida;

- Nos movimentos físiológicos devidos à respiração e movimentos do paciente durante a irradiação;

- No uso de equipamentos de imobilização e posicionamento do paciente (por exemplo, máscaras, apoio de cabeça, "vac-fix”);

- No valor real da DFS, se a leitura dosimétrica não é corrigida com relação a diferença entre a DFS real e a DFS planejada;

- No uso de campos assimétricos, por exemplo, em tratamentos tangenciais de mama:

- Nas possíveis flutuaçoes do rendimento da unidade de tratamento.

Como a medida de dose de entrada in vivo é comparada com a dose esperada, que é calculada pelo TPS ou por uma fórmula independente, a incerteza no cálculo da dose de entrada é outro fator que deve ser considerado. Essa incerteza depende dos seguintes parâmetros:

- Os algoritmos usados para o cálculo da dose;

- O método usado para o cálculo das unidades monitoras:

- O modo como as heterogeneidades são consideradas;

- O modo como os dados da unidade de tratamento foram adquiridos (por exemplo, a precisão com a qual $\mathrm{d}_{\max }$ foi determinado). 
A maioria dos centros de radioterapia usam um nivel de ação de $5 \%$ para a maioria dos tratamentos e o nível de tolerância normalmente coincide com esse nível, com a filosofia de que qualquer desvio maior que $5 \%$ deve ser investigado. $O$ procedimento recomendado para estabelecer um nivel de tolerância adequado para técnicas que envolvam alta precisão ou alta dose é investigar a exatidào alcançável da medida para a técnica em particular e aplicar como nivel de ação/tolerância dois desvios padrões da incerteza da medida.

A monitoração contínua da dosimetria in vivo após sua implementação é mandatória para reduzir os erros do processo de controle e possivelmente para ajustar os niveis de tolerância e ação quando eles forem considerados inadequados. Tal monitoração poderia ajudar a definir diferentes niveis para diferentes tipos de tratamentos e "setup" do feixe. Por exemplo, tornar-se-ia evidente se campos filtrados necessitariam niveis de tolerância/ação mais elevados do que campos não filtrados.

\section{Erros detectáveis}

i. Mau funcionamento do processo de controle de qualidade - pode levar a erros sistemáticos (envolve todos os pacientes) ou pode estar presente apenas em nivel individual. Os erros sistemáticos são erros (ou deslocamentos) nos fatores de calibração dos dosímetros ou erros nos fatores de correção (ou omissão de algum fator de correção necessário). Podem também ser induzidos por cálculos errôneos (com ou sem TPS) da dose de entrada. Os erros individuais no processo de controle de qualidade para dose de entrada são os seguintes:
a. Erro no cálculo da dose de entrada (uso errado do fator de calibração e fatores de correção);
b. Registro incorreto da DFS;
c. Erro na leitura ou no registro do sinal medido in vivo;
d. Erro de posicionamento do dosimetro;
e. Fixação ruim do dosimetro.

ii. Desvios no processo de tratamento (erros humanos) - são divididos em três categorias: 
a. Erros humanos na origem e transferência de dados. Os parâmetros que a dosimetria de entrada in vivo pode detectar. com ou sem o uso do sistema de planejamento para o cálculo da dose de entrada são: ausència involuntária ou presença de modificadores do feixe (filtro, bandeja, bloco, compensadores); e modalidade de tratamento (fótons ou elétrons) e energia;

b. Erros devido às interrupções ou mau funcionamento da unidade de tratamento. Medidas de dose de entrada in vivo podem facilmente detectar interrupções da unidade de tratamento e grandes variaçooes no rendimento do feixe, bem como mau funcionamento ou uso incorreto de novos "software" ou um "upgrade" do "software" para o cálculo da unidade monitora;

c. Discrepâncias entre o posicionamento no plano de tratamento e o posicionamento na administração da dose. Movimentação do paciente ou mudança na sua espessura, devido a um ganho ou perda de massa, representam outras fontes de erros de posicionamento. A medida de dose de entrada pode detectar erros de "setup" do paciente em relação ao feixe (distância fonte-superficie incorreta), bem como erros de espessura do paciente quando essa é reavaliada com o objetivo de encontrar a origem de diferenças grandes na distância fonte-superficie.

\subsubsection{Avaliação dos dados da dosimetria in vivo}

\section{Ações após a primeira medida de dose in vivo}

Caso o resultado da primeira medida esteja fora do nível de tolerância/ação, deve-se verificar, primeiramente, o "setup" do tratamento e os parâmetros de tratamento. Os erros mais comuns são: diferenças na DFS e posicionamentos incorretos do dosimetro, que podem ser verificados por meio de radiografias do local. Possiveis diferenças na DFS devido ao uso de dispositivos de imobilização ou "bolus" devem ser corrigidas aplicando-se o fator de correção apropriado para o inverso do quadrado da distância.

Caso a causa da discrepância não seja conhecida, deve-se realizar a verificação da congruência de todos os dados técnicos e dosimétricos do plano de tratamento/simulação: concordância entre a unidade monitora efetivamente fornecida e a planejada; a exatidão do 
cálculo da unidade monitora e; o uso correto de filtros e blocos. Se a dose medida in vivo com campos bloqueados for menor do que a esperada, deve-se verificar a posição do dosímetro. especialmente se o bloco estiver proximo do centro do campo. De qualquer forma, é recomendável realizar uma segunda medida in vivo.

A medida de dose de entrada com o dosímetro e uma câmara de ionização em um objeto simulador sólido nas mesmas condições clinicas de tratamento (DFS, tamanho de campo, rotação do sistema suporte funcional e colimador, bloco, etc.) pode ser útil para encontrar a causa da discrepancia. Se o desvio entre a dose medida no objeto simulador com o TLD e a dose calculada é aceitável, esse pode ser atribuido à dificuldade no posicionamento do TLD sobre a pele do paciente. Se a dose medida com a câmara de ionização está de acordo com a dose esperada, mas a leitura do TLD não está correta, o desvio no sinal TL pode ser devido a uma calibração ruim ou fatores de correção errados. Se a dose medida no objeto sinulador com a câmara de ionização não coincide com a dose esperada. erros de cálculo de dose podem estar presentes. As principais causas de persistência das discrepâncias são as seguintes:

- Dificuldades no "setup" do paciente: são mais facilmente detectadas se as leituras do TLD não são corrigidas pelo inverso do quadrado da distância;

- Incerteza na leitura do TLD devido ao posicionamento critico (campos tangenciais, campos filtrados, etc) ou à ausência de fatores de correção;

- Cálculo incorreto da dose de entrada pelo TPS.

\section{Monitorando a dose in vivo}

O monitoramento contínuo dos dados da dosimetria in vivo pode indicar a necessidade de um ajuste dos niveis de tolerância/açào. Análise estatística dos desvios entre a dose de entrada medida e a esperada pode fornecer informações que sugerem possiveis campos de investigação ou possiveis melhorias do processo de controle de qualidade (por exemplo, uma avaliação mais acurada dos fatores de correção do TLD). A distribuição dos desvios pode revelar erros sistemáticos relacionados às técnicas de tratamentos especificas ou aos métodos de cálculos. 


\subsection{Objetivos}

\section{Objetivo geral}

O objetivo desse trabalho é apresentar um método para implementação da dosimetria in vivo da dose de entrada na rotina clínica em tratamentos radioterápicos com feixe de fótons de alta energia, utilizando dosímetros termoluminescentes de LiF.

\section{Objetivo específico}

Avaliar a dose de entrada em pacientes com câncer de mama. 


\section{MATERIAIS E MÉTODOS}

\subsection{Dosímetros termoluminescentes}

Foram disponibilizadas para este estudo 150 pastilhas de LiF:Mg;Ti (TLD-100. Harshaw) com dimensões nominais de $3,17 \mathrm{~mm} \times 3.17 \mathrm{~mm} \times 0,89 \mathrm{~mm}$.

\subsection{O sistema de leitura}

Basicamente, uma leitora TL é constituida de um dispositivo para aquecer o dosímetro e uma fotomultiplicadora para captar a luz que o dosimetro emite.

O sistema de leitura Harshaw modelo 3500 TLD empregado nas leituras TL consiste de dois componentes principais: a leitora TLD e o software WinREMS (Windows Radiation Evaluation and Management System) instalado em um computador pessoal.

A leitora possui uma prancheta metálica sobre a qual é colocado o dosímetro que, por sua vez, é aquecido por contato com um sistema de "feedback". Este sistema produz uma rampa linear de temperatura entre a temperatura ambiente a $400^{\circ} \mathrm{C}$, dividida em três segmentos: Préaquecimento, Aquisição e Aquecimento. cada um com tempos e temperaturas independentes.

Para melhorar a acurácia das respostas à baixa exposição e para aumentar a vida da prancheta, o modelo 3500 opera com um fluxo de nitrogênio ao redor da prancheta. O fluxo de nitrogênio elimina o oxigènio presente na área da prancheta e, conseqüentemente. elimina os indesejados sinais TL induzidos pelo oxigènio. O nitrogènio é também distribuido através da Câmara do Tubo Fotomultiplicador para eliminar a unidade causada por condensação. 


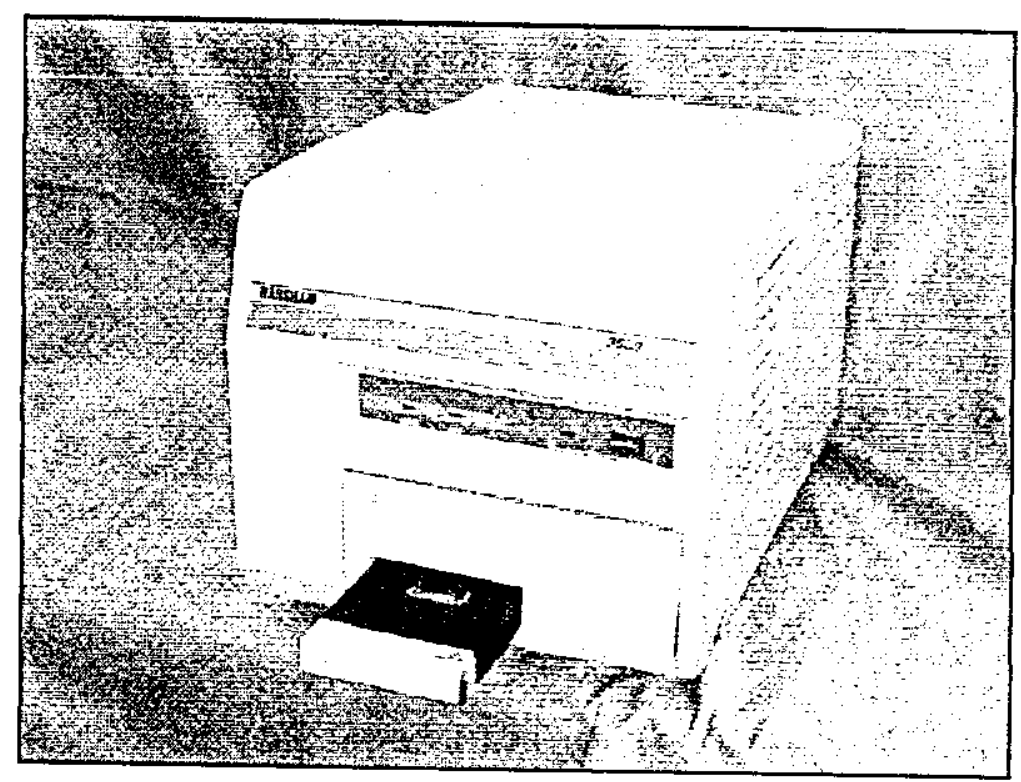

FIGURA 7 - Leitora TL Harshaw Modelo 3500TLD. Fonte - Manual Harshaw 3500TLD

\subsection{Procedimento de seleção dos TLDs}

As irradiações para seleção dos TLDs foram realizadas com um feixe de fótons de $6 \mathrm{MV}$, produzido pelo acelerador linear de uso clínico (MX-2, Siemens) descrito na seção 2.10 pertencente à Associação Beneficente de Senhoras Hospital Sírio Libanês.

Um forno dedicado ("Thermo Electron Corporation") foi utilizado no tratamento térmico do TLD e o sinal foi lido em uma leitora TL Harshaw modelo 3500TLD. O ciclo de tratamento térmico consistiu em um aquecimento das pastilhas a $400{ }^{\circ} \mathrm{C}$ por uma hora (tratamento térmico pré-irradiação a alta temperatura), seguido por duas horas a $100^{\circ} \mathrm{C}$ (tratamento térmico pré-irradiação a baixa temperatura). Antes de cada leitura o TLD foi aquecido a $100{ }^{\circ} \mathrm{C}$ por dez minutos (tratamento térmico pós-irradiação ou pré-leitura). Durante o processo de leitura do sinal $\mathrm{TL}$, a leitora é pré-aquecida atingindo a temperatura de $50{ }^{\circ} \mathrm{C}$; a partir desta temperatura, até atingir $300^{\circ} \mathrm{C}$ a uma taxa de $10^{\circ} \mathrm{C}$ por segundo, ocorre a aquisição do sinal.

Os TLDs, previamente identificados, foram submetidos a cinco ciclos dosimétricos (tratamento térmico pré-irradiação; irradiação; tratamento térmico pré-leitura e; leitura). Os TLDs foram irradiados com a mesma dose em cada um dos cinco ciclos, previamente estabelecida como sendo igual a $1 \mathrm{~Gy}$.

Determinou-se a média aritmética e o desvio padrão das cinco leituras individuais de cada dosimetro por meio das Equações 7 e 8, respectivamente. 
A média aritmética é a melhor estimativa disponível do valor esperado de uma grandeza $q$ que varia aleatoriamente e para a qual $n$ observaçòes independentes $q_{k}$ foram obtidas sob as mesmas condições de medição:

$$
\bar{q}=\frac{1}{n} \sum_{k=1}^{n} q_{k}
$$

As observações individuais $q_{k}$ diferem em valor por causa de variações aleatórias nas grandezas de influência dos efeitos aleatórios. A variância experimental $s^{2}\left(q_{k}\right)$ das observações é dada por:

$$
s^{2}\left(q_{k}\right)=\frac{1}{n-1} \sum_{k=1}^{n}\left(q_{k}-\bar{q}\right)^{2}
$$

A raiz quadrada positiva desta variância $s\left(q_{k}\right)$ é denominada desvio padrão experimental ou simplesmente desvio padrão $(\sigma)$ e caracteriza a variabilidade dos valores $q_{k}$ observados, mais especificamente, sua dispersão em torno da média. A variância da média, $s^{2}(\bar{q})$, é dada por:

$$
s^{2}(\bar{q})=\frac{s^{2}\left(q_{k}\right)}{n}=\frac{1}{n(n-1)} \sum_{k=1}^{n}\left(q_{k}-\bar{q}\right)^{2}
$$

onde a raiz quadrada positiva de $s^{2}(\bar{q})$ é o desvio padrão experimental da média $s(\bar{q})$. Este valor quantifica quão bem $\bar{q}$ estima o valor esperado de $q$ e qualquer um dentre eles pode ser usado como medida da incerteza de $\bar{q}$. Esta estimativa da variabilidade das medidas devido a erros aleatórios por meio do desvio padrão supõe que a freqüência das medidas obedece à distribuição gaussiana. O procedimento estatistico usualmente indicado para o tratamento de medidas experimentais consiste justamente em fazer os cálculos acima indicados e expressar o valor de uma grandeza $q$ usando os dados obtidos com as relaçòes (7) e (9): 
Valor da grandeza $=$ média das $n$ medidas \pm desvio padrão da média

$$
q=\bar{q} \pm s(\bar{q})
$$

O uso das expressões acima pressupõe que, durante a realização de uma série de medidas, não ocorreram erros grosseiros, que os erros sistemáticos ou estiveram ausentes, ou foram devidamente compensados, ou são de ordem de grandezas inferior aos erros aleatórios; e que todas as demais fontes de erro contribuiram aleatoriamente, ora para aumentar, ora para diminuir o valor da grandeza. Ainda pode-se representar o desvio padrão da média na seguinte forma:

$$
q=\bar{q} \pm \frac{s(\bar{q})}{\bar{q}} 100 \%
$$

Foram selecionadas setenta e nove pastilhas que apresentaram variação da sensibilidade dentro de $\pm 5 \%(1 \sigma)$ e reprodutibilidade dentro de $\pm 3 \%(1 \sigma)$.

\subsection{Capa de equilíbrio eletrônico}

De acordo com o protocolo Estro, "booklet" nr.1, que recomenda a utilização de uma capa para garantir reprodutibilidade das medidas, alguns dos TLDs selecionados foram calibrados para medida de dose de entrada na presença de uma capa de equilibrio eletrônico confeccionada para esta finalidade.

Em um feixe de fótons de $6 \mathrm{MV}$, o objetivo é obter uma espessura de material equivalente à àgua ao redor do dosimetro TL entre 1.5 a $2,0 \mathrm{~cm}$, o que representa um bom compromisso para a profundidade de dose máxima (Jordan, 1996), de modo a impedir que a leitura do TLD seja realizada em uma região de alto gradiente de dose.

O efeito Compton é o modo predominante de interação para feixes de fótons de megavoltagem no intervalo clínico. Sendo assim a espessura da capa de equilibrio eletrònico de um determinado material $\left(\mathrm{d}_{\mathrm{m}}\right)$ multiplicada pela razão das densidades eletrônicas do material 
$\left(\rho_{c}\right)_{m}$ e da água $\left(\rho_{c}\right)_{m o}$ fornece a espessura equivalente de água. Conseqüentemente será alcançadia aproximadamente, a mesıma atenuaçào do feixe.

$$
d_{m} \frac{\left(\rho_{c}\right)_{m}}{\left(\rho_{1}\right)_{H 20}}=d_{H 2 t}
$$

A capa de equilíbrio eletrônico foi construída com resina epóxi (nome comercial: durepóxi) de densidade física de $1,9325 \mathrm{~g} / \mathrm{cm}^{3}$. com geometria semi-esférica de raio $1.12 \mathrm{~cm}$ (equivalente. em termos de densidade física. a $2.16 \mathrm{~cm}$ de água). No centro da base da semiesfera foi aberto um espaço para acomodar um TLD, a fim de posicioná-lo no eiso central do campo durante as irradiações (FIG. 8).

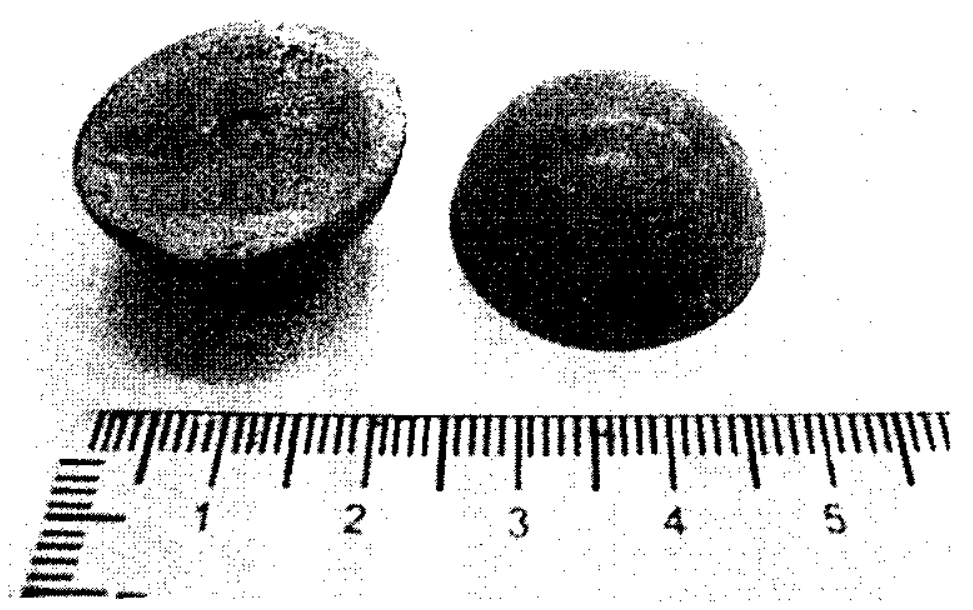

FIGURA 8 - Capa de equilíbrio eletrònico confeccionada com resina epóxi

Uma resina epóxi ou poliepóxido é um plástico termofixo que se endurece quando se mistura com um agente catalizador ou "endurecedor". A FIG. 9 apresenta a estrutura química do polimero. 


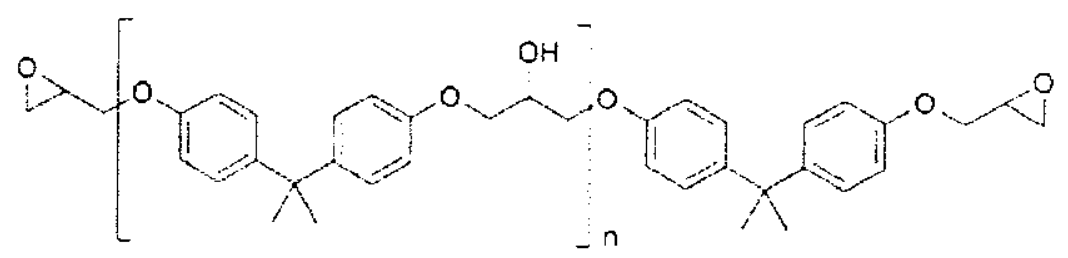

FIGURA 9 - Estrutura química do polímero epóxi. Fonte - Wikipédia, a enciclopédia livre.

Seguindo o procedimento adotado por Swinnen et al. (2004) foi investigada a atenuação causada pelo conjunto (capa de equilíbrio eletrônico e dosímetro) no campo de tratamento. Um filme dosimétrico (ECL Kodak V) foi colocado a $5 \mathrm{~cm}$ de profundidade no objeto simulador de acrílico. $\mathrm{O}$ dosímetro no interior da capa foi posicionado na superficie do objeto simulador, no centro do campo de irradiação de área $10 \times 10 \mathrm{~cm}^{2}$, a uma distância fonte-superficie de $100 \mathrm{~cm}$. Um filme de referência foi exposto nas mesmas condições, mas sem o dosímetro. Os perfis do feixe através do eixo central na profundidade de $5 \mathrm{~cm}$ foram obtidos por meio de um scanner de filme (VXR-12, Vidar). As densidades óticas foram convertidas em doses relativas por meio do software OmniPro (Scanditronix/Wellhofer). Como o dosímetro foi colocado no centro do campo, os perfis relativos de dose foram normalizados a $3 \mathrm{~cm}$ do eixo central.

\subsection{Curva de calibração}

A linearidade da resposta TL em função da dose absorvida foi analisada com trinta e cinco pastilhas. Grupos contendo cinco pastilhas cada foram irradiados com 5, 25, 50, 75, $100,150,200,250$ e 300 unidades monitoras, a uma distância foco-superficie de $100 \mathrm{~cm}$, em um campo $10 \times 10 \mathrm{~cm}^{2}$, em uma profundidade de $6 \mathrm{~cm}$ no objeto simulador. A dose por unidade monitora foi determinada usando uma câmara de ionização posicionada na mesma profundidade, imediatamente após a irradiação dos TLDs. Foram determinados a média e o desvio padrão das cinco leituras de cada grupo.

\subsection{Procedimento de calibração dos TLDs}

Foi realizada a calibração de vinte e duas pastilhas das setenta e nove previamente selecionadas que apresentaram um menor desvio padrão percentual. Cada uma das pastilhas dentro da capa de equilíbrio eletrônico foi posicionada na superficie do objeto simulador de acrílico, no centro de um campo $10 \times 10 \mathrm{~cm}^{2}$ na DFS de $100 \mathrm{~cm}$. Os vinte e 
dois dosímetros foram submetidos a três ciclos dosimétricos, tendo sido irradiados com uma dose de 1 Gy em cada um dos três ciclos.

O sinal do TLD foi comparado com a dose absorvida determinada com uma câmara de ionização, posicionada no centro do campo, na profundidade de dose máxima: $1,5 \mathrm{~cm}$ de água, definida como a dose de entrada. $O$ fator de calibração $\left(\mathrm{F}_{\text {cal }}\right)$ foi determinado por meio da Eq. (2).

\subsection{Determinação dos fatores de correção}

Seguindo o método descrito na seção 1.3.1.5, foram determinados os seguintes fatores de correção:

1. Fatores de correção para tamanho de campo: campos quadrados de lados $5,10,15$, 20,25 e $30 \mathrm{~cm}$.

2. Fatores de correção para distância foco-superficie: $90,95,100,105$ e $110 \mathrm{~cm}$.

3. Fatores de correção para filtros físicos: $15^{\circ}, 30^{\circ}$ e $45^{\circ}$.

4. Fatores de correção para ângulo de incidência do feixe: $45^{\circ}, 50^{\circ}, 55^{\circ}$ e $60^{\circ}$.

Os intervalos de medidas dos fatores de correção acima mencionados foram escolhidos com base em valores médios dos parâmetros de tratamento de mama e modificadores de feixe normalmente empregados no Hospital Sírio Libanês.

\subsection{Seleção dos objetos simuladores}

O objeto simulador de acrílico (PMMA) utilizado tem densidade de $1,19 \mathrm{~g} / \mathrm{cm}^{3}$, densidade eletrônica e número atômico efetivo relativo à água de 1,16 e 1,02, respectivamente. É composto de um conjunto de placas quadradas de área $30 \times 30 \mathrm{~cm}^{2}$ de diferentes espessuras $(0,5 \mathrm{~mm}, 1,0 \mathrm{~mm}, 2,0 \mathrm{~mm}, 1,0 \mathrm{~cm}$ e $2 \mathrm{~cm})$. Nesse trabalho foram utilizadas dez placas de $1,0 \mathrm{~cm}$ cada para fornecer um adequado retro-espalhamento, uma placa de $1,0 \mathrm{~cm}$ para posicionamento dos TLDs em furos (FIG. 10) e três placas $(0,5 \mathrm{~mm}$, $2,0 \mathrm{~mm}$ e $1,0 \mathrm{~cm}$ ) para garantir o equilibrio eletrônico. 


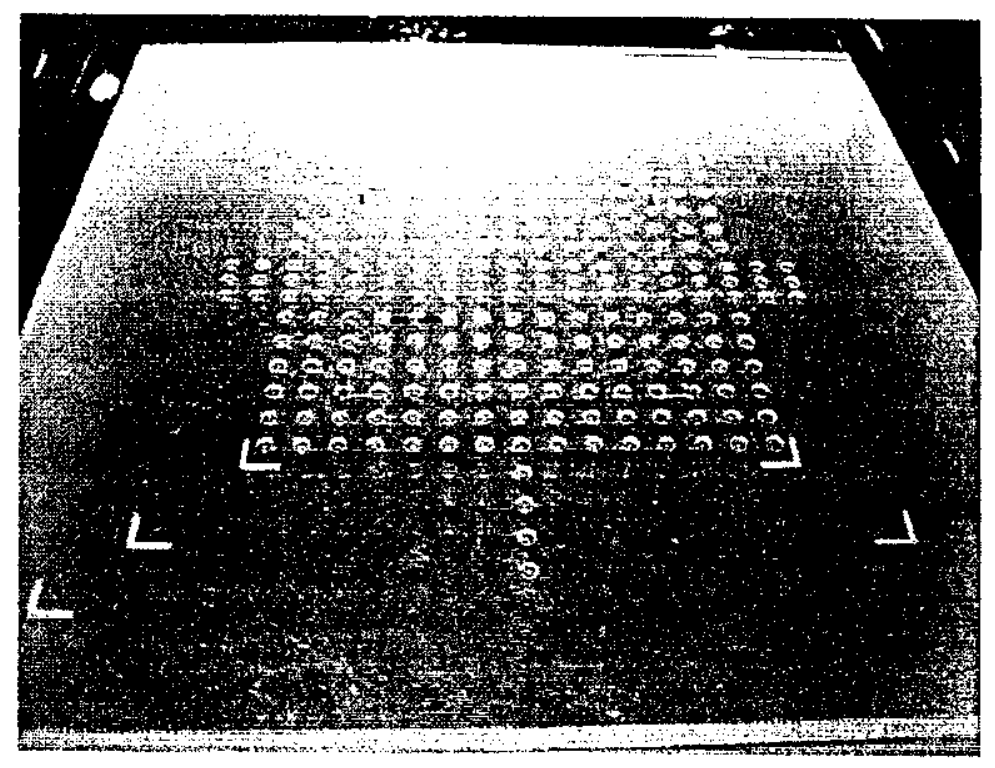

FIGURA 10 - Placa de acrílico utilizada para posicionamento dos TLDs em furos durante o processo de seleção das pastilhas

O objeto simulador de mama utilizado consistia de um molde de mama feito com material equivalente ao tecido (cera odontológica), com densidade fisica de $0,93 \mathrm{~g} / \mathrm{cm}^{3}$, posicionado sobre placas de acrilico garantindo suficiente retro-espalhamento (FIG. 11).

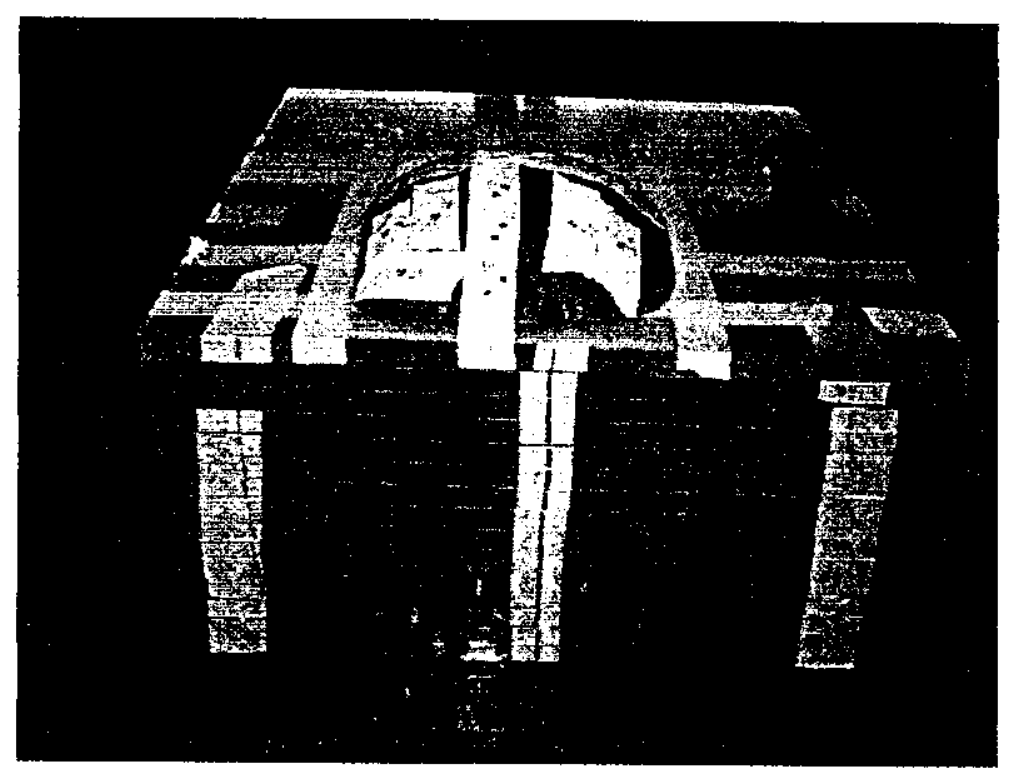

FIGURA 11 - Objeto simulador de mama sobre objeto simulador de acrílico 


\subsection{Medidas em objetos simuladores}

$\Lambda$ irradiação para seleção das pastilhas foi feita no objeto simulador de acrilico. Uma das placas foi utilizada para posicionar os TLDs em furos confeccionados com profundidade de $1 \mathrm{~mm}$ e diâmetro igual à diagonal da superficie quadrada da pastilha. Cada irradiação foi realizada $\mathrm{cm}$ um campo $10 \times 10 \mathrm{~cm}^{2}$. DFS de $100 \mathrm{~cm}$ e 100 UMs. Os TLDs foram posicionados na profundidade de dose máxima para a energia empregada: $1.25 \mathrm{~cm}$ de acrílico correspondendo a $1.5 \mathrm{~cm}$ de água. A dose na profundidade de dose máxima foi determinada com uma câmara de ionização cilindrica (NE $2571-0.6 \mathrm{~cm}^{3}$ ). colocada dentro do objeto simulador. e a carga gerada na câmara foi coletada por um eletrômetro (Keithley).

A consistência do procedimento de calibração. ou seja. a exatidão da determinação da dose de entrada com TLD foi avaliada por meio de irradiaçòes no objeto simulador de mama. Esta exatidão pode ser determinada pela razão da dose determinada com TLD e o valor obtido pelo sistema de planejamento.

O objeto simulador de mama passou por uma simulação para determinação da posição de tratamento de referência e. em seguida. por uma tomografia. As imagens da tomografia foram transferidas para o sistema de planejamento. Foram simulados tratamentos com campo obliquo único variando-se os parâmetros envolvidos no tratamento: DFS; tamanho de campo; ângulo do filtro físico: e ângulo de incidência do feixe (TAB. 6). Todos os campos foram irradiados com I00 UM.

O sistema de planejamento do tratamento utilizado no serviço de radioterapia do Hospital Sírio L ibanês. Helax, fornece o valor da dose de entrada no eixo central do feixe. que pode ser obtido por meio do relatório geral de avaliação disponível para impressão pelo sistema. No caso de o eixo central estar bloqueado, o usuário tem a possibilidade de mover o ponto correspondente de dose e a nova posição é indicada no relatório geral por um asterisco $(*)$. Este recurso. denominado dose pontual ("point-dose"). permite conhecer com exatidão a dose absorvida cm um ponto qualquer situado no interior do volume de tratamento, distante o suficiente da superfïcie do volume para que exista a condição de equilíbrio eletrônico. 
O valor absoluto da dose no ponto de medida foi determinado no eixo central do campo de irradiação. a $1.6 \mathrm{~cm}$ abaixo da superfície do objeto simulador de mama (correspondendo a $1.5 \mathrm{~cm}$ de água).

TABE:LA 6 - Parâmetros dos tratamentos simulados no objeto simulador de mama

\begin{tabular}{ccccc} 
Medida & DFS $(\mathrm{cm})$ & Campo $\left(\mathrm{cm}^{2}\right)$ & Filtro & Feixe \\
\hline I & 100 & $10 \times 10$ & não & $0^{\circ}$ \\
2 & 100 & $10 \times 10$ & não & $60^{\circ}$ \\
3 & 100 & $10 \times 10$ & $15^{\circ}$ & $0^{\circ}$ \\
4 & 100 & $10 \times 10$ & $30^{\circ}$ & $0^{\circ}$ \\
5 & 100 & $10 \times 10$ & $45^{\circ}$ & $0^{\circ}$ \\
6 & 100 & $14 \times 14$ & não & $0^{\circ}$ \\
7 & 90 & $10 \times 10$ & não & $0^{\circ}$ \\
8 & 88 & $10 \times 10$ & $15^{\circ}$ & $51^{\circ}$ \\
9 & 89 & $10 \times 10$ & $30^{\circ}$ & $53^{\circ}$ \\
10 & 91 & $10 \times 10$ & $45^{\circ}$ & $55^{\circ}$ \\
11 & 88 & $12 \times 12$ & $15^{\circ}$ & $52^{\circ}$ \\
12 & 89 & $11 \times 11$ & $30^{\circ}$ & $54^{\circ}$ \\
13 & 91 & $13 \times 13$ & $45^{\circ}$ & $56^{\circ}$ \\
14 & 92 & $14 \times 14$ & $30^{\circ}$ & $58^{\circ}$ \\
15 & 90.5 & $10.5 \times 10.5$ & $15^{\circ}$ & $60^{\circ}$ \\
& & & &
\end{tabular}

\subsection{Unidades de tratamento}

Foram utilizadas duas unidades de tratamento no tratamento de câncer de mama das pacientes selecionadas para este estudo, ambas pertencentes ao serviço de radioterapia do Hospital Sirio Libanês. O acelerador linear modelo MX-2 (Siemens) que produz feixe de fótons de energia de $6 \mathrm{MV}$ e o acelerador linear modelo KD-2 (Siemens) que produz tanto feixe de fötons com energias de 6 e $18 \mathrm{MV}$ quanto de elétrons com energias de 6.9.12.18 e 21 MeV.

As duas unidades estão equipadas com um sistema automático de verificação (Lantis) que verilica. antes de cada aplicação do tratamento. o número de unidades monitoras. os parâmetros geométricos ajustáveis e os dispositivos modificadores do feixe. Os aceleradores foram calibrados para fornecer um rendimento de $0.01 \mathrm{~Gy}$ por unidade monitora nas condiçoes de referência. ou seja. na profundidade de dose máxima. em um objeto simulador de água, tamanho de campo de $10 \times 10 \mathrm{~cm}^{2}$. a uma distância da fonte à superfície do objeto simulador de $100 \mathrm{~cm}$. A laxa de dose constante foi ajustada em $200 \mathrm{UM} / \mathrm{min}$ para o feixe de $6 \mathrm{MV}$. 


\subsection{Téenica de tratamento e planejamento da dose}

No serviço de radioterapia do Hospital Sírio Libanês. a paciente é posicionada na posiçào supino sobre um dispositivo imobilizador, denominado "vac-loc". modelado em um plano inclinado sobre uma rampa de isopor para compensar a curvatura da parede torácica. O braço contra-lateral à mama a ser tratada é alinhado ao longo do corpo e o braço ipsilateral é posicionado para cima em abdução, com a cabeça direcionada para o lado do braço contra-lateral.

A mama é irradiada por um par de campos tangenciais assimétricos, com um feixe de fótons de $6 \mathrm{MV}$. Na maioria dos tratamentos de mama nesse serviço é incluído um campo externo modulado e a técnica em questão é denominada "field-in-field". com o objetivo de homogeneizar a dose. Em alguns casos também se aplica. além do campo externo modulado, um campo interno modulado. São três as prescrições de tratamento adotadas: 25 frações com dose de 1,8 Gy por fiaçào totalizando 45 Gy com um feixe de fótons, seguidas de uma dose complementar de 10 Gy divida em 5 frações com um feixe de elétrons; ou 28 frações com dose de 1.8 Gy por fração totalizando 50.4 Gy: ou 50 Gy distribuídos em 25 frações com dose de 2.0 Gy por fração.

Todos os campos de tratamento incluem filtros físicos para compensação da irregularidade do contorno do paciente.

\subsection{Medidas in vivo}

Após a aprovação do conselho de ética, as medidas de dose de entrada in viro foram realizadas em 5 pacientes tratadas com feixe de fótons de $6 \mathrm{MV}$ no serviço de radioterapia do Hospital Sírio Libanês. A dose de entrada foi medida no eixo central do campo tangencial interno e comparada com a dose de entrada esperada.

Antes do início do tratamento, o dosímetro foi fixado sobre a pele da paciente com fita adesiva e permaneceu no local somente durante a aplicação do campo interno (FIG. 12). Antes de fixar o dosimetro, foi verificada a distância fonte-superfície e o seu valor foi comparado com o valor definido durante a simulação e utilizado para o planejamento do tratamento. Desse modo. quaisquer possiveis efeitos sobre a dose prescrita. devido a discrepâncias pequenas entre as condiçós de planejamento e de tratamento. poderiam ser avaliados durante a interpretação da medida in vivo. 
As medidas de dose de entrada foram realizadas durante três dias consecutivos para cada paciente, a fim de investigar a exatidão e a reprodutibilidade do tratamento. A média de todos os desvios observados de todas as medidas de um mesmo paciente foi calculada para obtenção da melhor estimativa da diferença entre a dose fornecida e a dose prescrita no ponto de medida de interesse.

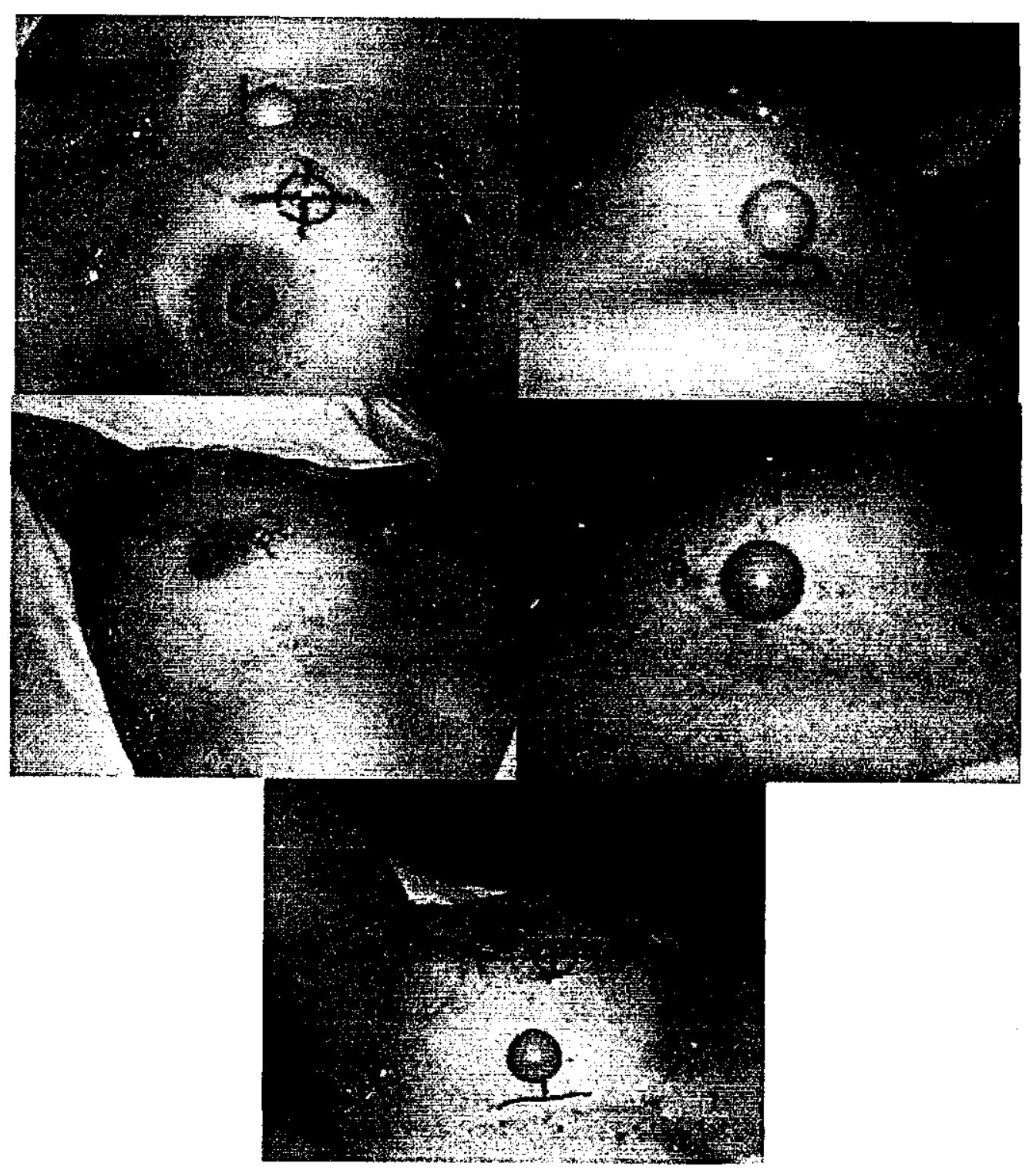

FIGURA 12 - TLD dentro da capa de equilíbrio eletrônico fixado na pele das cinco pacientes no campo interno de tratamento 
- Medidas de dose de entrada (e saída) para todos os pacientes durante uma ou duas sessões do tratamento - o estudo de Leunens et al. (1992) mostrou que a transferência errônea de dados como, por exemplo, durante a preparação do plano de tratamento, pode levar a uma sub-dosagem ou sobre-dosagem de mais de 5\% para 5\% dos casos, e esses erros poderiam ter sido rastreados por meio da dosimetria in vivo em $96 \%$ dos casos.

- Dosimetria in vivo para um número limitado de pacientes irradiados com técnicas padrões - no hospital universitário St. Rafael em Leuven, um dos primeiros hospitais a estabelecer tal programa de dosimetria in vivo, foram rastreados vários erros de transferências de dados no processo de planejamento do tratamento. Em Leuven e em um hospital em Villejuif, um estudo durante irradiação de campo "mantle" mostrou que, para 34\% dos casos, ocorreram erros no "setup" dos blocos de blindagem. Em Villejuif, para 22\% dos "setups", resultou um erro no fornecimento da dose de mais de $5 \%$

Com base nos resultados dos diversos estudos pôde-se concluir que nos centros que dispunham de equipamentos modernos com sistemas de verificação bem como de programas de controle de qualidade, ainda se constatava um erro sistemático maior que $5 \%$ na liberação da dose para $0,5-1 \%$ dos tratamentos dos pacientes. Os autores concluíram que a verificação da dose do paciente deveria ser uma parte essencial de um programa de controle de qualidade em um departamento de radioterapia e, como a comunidade da radioterapia está fazendo a transição de terapias convencionais $2 \mathrm{D}$ para $3 \mathrm{D}$ e para terapia com feixe de intensidade modulada, IMRT, recomendam que cada nova técnica de tratamento seja verificada sistematicamente para alguns pacientes, e realizar a dosimetria in vivo algumas vezes para cada paciente para situações onde se pode minimizar os erros na administração da dose.

Huyskens et al. (2001) relataram a implantação da dosimetria de entrada in vivo em grande escala em um centro de radioterapia. A medida da dose no paciente é realizada no início do tratamento, nas primeiras três frações, de modo a tornar possível corrigir quaisquer erros detectados. As medidas in vivo são realizadas com diferentes tipos de diodos, o que permite avaliar flutuações estatísticas devido às várias características dos diodos. Foram aplicados fatores de correção para tamanho de campo e variações na resposta em diferentes distâncias fonte-superfície (DFS) no intervalo de energia de 8 a 18 MV. A dependência com a temperatura foi considerada no procedimento de calibração. Foram utilizados diodos de forma cilíndrica em campos de tratamento tangenciais, conseqüentemente, não foram necessárias correções para dependência direcional. Os níveis de tolerância e níveis de ação estabelecidos para diferentes locais de tratamento estão listados na TAB. 5. 


\subsection{Registro da medida}

Todas as medidas foram registradas manualmente em uma planilha Excel elaborada para essa finalidade (FIG. 14). Os fatores de calibração e de correção foram aplicados na planilha e a dose calculada foi comparada com o valor esperado.

\begin{tabular}{|c|c|c|c|c|c|c|c|c|c|c|c|}
\hline \multirow{2}{*}{ Paciente } & \multirow{2}{*}{ Medida } & \multirow{2}{*}{ TLD } & \multirow{2}{*}{$\begin{array}{c}\text { Leitura } \\
\text { (nC) }\end{array}$} & \multirow{2}{*}{$\begin{array}{c}\text { Feal } \\
(\text { Gy/nC) }\end{array}$} & \multicolumn{4}{|c|}{ Fator de Correção } & \multicolumn{2}{|c|}{ Dose (Gy) } & \multirow{2}{*}{$\begin{array}{l}\text { Dif. } \\
(\%)\end{array}$} \\
\hline & & & & & Filtro & Campo & DFS & Incidência & TLD & TPS & \\
\hline \multirow{3}{*}{$\mathbf{1}$} & 1 & 8 & 718.6 & 0.1664 & 1.0407 & 0.9985 & 1,0209 & $0 . \overline{9680}$ & 1.228 & $1.1 \overline{73}$ & 4.5 \\
\hline & 2 & 65 & 726,9 & 0.1590 & 1.0407 & 0.9985 & 1,0209 & 0.9680 & 1,187 & 1.173 & 1.2 \\
\hline & 3 & 114 & 725.4 & 0.1623 & 1.0407 & 0.9985 & 1.0209 & 0,9680 & 1,209 & 1.173 & 3.0 \\
\hline \multirow{3}{*}{2} & 1 & 8 & $882 . \overline{6}$ & 0.1664 & 1.0048 & 1.0065 & 1.0201 & 0.9690 & 1.468 & 1,416 & 3.6 \\
\hline & 2 & 65 & 875,2 & 0.1590 & 1.0048 & 1.0065 & 1.0201 & 0.9690 & 1.391 & 1,416 & -1.8 \\
\hline & 3 & 114 & 892.1 & 0.1623 & 1.0048 & 1.0065 & 1.0201 & 0,9690 & 1.448 & 1.416 & 2.2 \\
\hline \multirow{3}{*}{3} & 1 & 8 & $903 \overline{3}$ & 0.1664 & 1.0048 & 1.0042 & 1,0187 & 0,9735 & 1.504 & 1.463 & 2.7 \\
\hline & 2 & 65 & 910,1 & 0.1590 & 1.0048 & 1.0042 & 1,0187 & 0.97 .35 & 1.448 & 1.46 .3 & -1.0 \\
\hline & 3 & & & & & & & & & & \\
\hline \multirow{3}{*}{4} & $\mathbf{1}$ & 107 & 682.9 & 0.1627 & 1.0399 & 1.0127 & 1.017 & 0.9699 & 1.154 & 1,152 & 0.2 \\
\hline & 2 & 114 & 707.8 & 0.1623 & 1.0399 & 1.0127 & 1.017 & 0,9699 & 1.193 & 1.152 & 3.5 \\
\hline & 3 & 126 & 690,0 & 0.1596 & 1.0399 & 1.0127 & 1,017 & 0,9699 & 1.144 & 1,152 & -0.7 \\
\hline \multirow[b]{2}{*}{5} & 1 & 107 & 841,3 & 0.1627 & 1.0399 & 1.0062 & 1.018 & 0.9690 & 1.413 & $1,4 \overline{35}$ & -1.5 \\
\hline & 2 & 126 & 846.6 & 0.1596 & 1.0399 & 1.0062 & 1,018 & 0,9690 & 1.395 & 1.435 & -2.9 \\
\hline
\end{tabular}

FIGURA 14 - Planilha Excel elaborada para registro das medidas in vivo 


\section{RESULTADOS E DISCUSSÃO}

\subsection{Seleção dos dosímetros termoluminescentes}

Na TAB. 7 está apresentada a média das cinco leituras $\left(\mathrm{L}_{\text {múdia }}\right)$ de cada TLD. bem como o desvio padrão percentual $(\sigma(\%))$ das leituras individuais. Encontram-se destacados o número do TLD e o respectivo desvio padrào percentual dos TLDs que apresentaram uma dispersão em torno da média menor ou igual a $3.0 \%$.

TABELA 7 - Leitura média e desvio padrão percentual das cinco leituras individuais dos cento e cinqüenta dosímetros termoluminescentes

\begin{tabular}{|c|c|c|c|c|c|}
\hline TLD & $\mathrm{L}_{\text {média }}(\eta \mathrm{C})$ & $\sigma(\%)$ & TLD & $\mathbf{L}_{\text {muédiiı }}(\eta C)$ & $\sigma(\%)$ \\
\hline 1 & 1122.8 & 4.3 & 76 & 1151.3 & 3,4 \\
\hline 2 & 1097.5 & 3.2 & 77 & 985.5 & 4.9 \\
\hline 3 & 1094.8 & 1,7 & 78 & 1041.8 & 5,9 \\
\hline 4 & 1052.4 & 1,8 & 79 & 1001.2 & 6.3 \\
\hline 5 & 1085.8 & 3,0 & 80 & 1043.0 & 3.5 \\
\hline 6 & 1160.6 & 2,4 & 81 & 1179.3 & 3.5 \\
\hline 7 & 1139.6 & 2,1 & 82 & 1076.2 & 8.5 \\
\hline 8 & 1032.8 & 1,3 & 83 & 1119.7 & 3,7 \\
\hline 9 & 1084.0 & 2,1 & 84 & 1051.4 & 1,5 \\
\hline 10 & 1079.2 & 2,0 & 85 & 1016.6 & 6,3 \\
\hline 11 & 1183,2 & 3,1 & 86 & 854.8 & 3.3 \\
\hline 12 & 1102.4 & 1,6 & 87 & 1003.8 & 3.8 \\
\hline 13 & 1061.6 & 1,8 & 88 & 1076.4 & 3.5 \\
\hline 14 & 1034,6 & 1,7 & 89 & 984.5 & 5.0 \\
\hline 15 & 1027.6 & 1,3 & 90 & 993.7 & 3.4 \\
\hline 16 & 1042,0 & 1,5 & 91 & 1011.0 & 3.3 \\
\hline 17 & 1072,2 & 4.2 & 92 & 1090,0 & 3,7 \\
\hline 18 & 1021,4 & 1,4 & 93 & 997.3 & 3.6 \\
\hline
\end{tabular}




\begin{tabular}{|c|c|c|c|c|c|}
\hline 19 & 1058.0 & 1,6 & 94 & 977.0 & 3.6 \\
\hline 20 & 1004.5 & 3,1 & 95 & 1007.2 & 3.5 \\
\hline 21 & 1069.0 & 2,2 & 96 & 1056.0 & 4.4 \\
\hline 22 & 1135.8 & 3.1 & 97 & 1008,6 & 3.1 \\
\hline 23 & 1100.0 & 3.6 & 98 & 1016.2 & 5.1 \\
\hline 24 & 1052.6 & 2,2 & 99 & 976.7 & 6.2 \\
\hline 25 & 1094.5 & 2,1 & 100 & 1008.3 & 3.3 \\
\hline 26 & 1039.0 & 1,9 & 101 & 1118.3 & 2,5 \\
\hline 27 & 1073.2 & 2,0 & 102 & 1069.5 & 2,5 \\
\hline 28 & 1084.6 & 2,6 & 103 & 1045.0 & 3.3 \\
\hline 29 & 1062.4 & 2,1 & 104 & 1063.3 & 2,3 \\
\hline 30 & 1120,8 & 1,9 & 105 & 1089.8 & 2,3 \\
\hline 31 & 1080.0 & 2,2 & 106 & 980.7 & 3.4 \\
\hline 32 & 1123.2 & 1,3 & 107 & 1043.8 & 1,7 \\
\hline 33 & 1024,0 & 1,2 & 108 & 1064.7 & 3.4 \\
\hline 34 & 1080.6 & 2,8 & 109 & 1056.2 & 2,5 \\
\hline 35 & 1197.4 & 4.0 & 110 & 1041,2 & 3.5 \\
\hline 36 & 1034,6 & 2,9 & 111 & 1033,1 & 4,0 \\
\hline 37 & 1116.4 & 2,0 & 112 & 1058.0 & 2,5 \\
\hline 38 & 1062.8 & 2,6 & 113 & 1007.8 & 3.2 \\
\hline 39 & 1076,0 & 2,6 & 114 & 1033.8 & 1,3 \\
\hline 40 & 1104.2 & 2,2 & 115 & 1103.2 & 2,6 \\
\hline 41 & 1157,3 & 3,1 & 116 & 1051.8 & 2,3 \\
\hline 42 & 1070.0 & 2,1 & 117 & 1022.2 & 3.5 \\
\hline 43 & 1159,4 & 3.2 & 118 & 1010,3 & 3.2 \\
\hline 44 & 1074.8 & 4,0 & 119 & 1017.7 & 6.8 \\
\hline 45 & 1044.4 & 3.2 & 120 & 1114.7 & 4.5 \\
\hline 46 & 1055,6 & 2,7 & 121 & 965.2 & 3.6 \\
\hline 47 & 1052.4 & 2,2 & 122 & 1052.2 & 4,0 \\
\hline 48 & 1069.6 & 1,9 & 123 & 1044.3 & 3.2 \\
\hline
\end{tabular}




\begin{tabular}{|c|c|c|c|c|c|}
\hline 49 & 1090.4 & 2,0 & 124 & 1032,0 & 2,4 \\
\hline 50 & 1081,2 & 2,8 & 125 & 1091,0 & 2,0 \\
\hline 51 & 1055.2 & 2,0 & 126 & 1036,7 & 1,4 \\
\hline 52 & 1155.6 & 2,2 & 127 & 1049,5 & 1,9 \\
\hline 53 & 1061.0 & 3.1 & 128 & 1033.1 & 3.9 \\
\hline 54 & 1071,2 & 2,0 & 129 & 1031,8 & 4.3 \\
\hline 55 & 1095.5 & 2,9 & 130 & 1016,6 & 3.1 \\
\hline 56 & 1130,0 & 3,1 & 131 & 1086,3 & 2,0 \\
\hline 57 & 1170,6 & 3,6 & 132 & 1034.0 & 1,4 \\
\hline 58 & 1089,0 & 2,2 & 133 & 1092,4 & 4,1 \\
\hline 59 & 1140.4 & 3,3 & 134 & 1087.3 & 4.3 \\
\hline 60 & 1020.6 & 1,5 & 135 & 1071.0 & 2,5 \\
\hline 61 & 1093.6 & 2,3 & 136 & 1058.5 & 3.2 \\
\hline 62 & 1120.8 & 1,9 & 137 & 1119.6 & 3.5 \\
\hline 63 & 1092,6 & 2,2 & 138 & 1060.8 & 5,2 \\
\hline 64 & 1050,8 & 2,4 & 139 & 1104.5 & 2,2 \\
\hline 65 & 1036,8 & 1,4 & 140 & 1012,9 & 3.2 \\
\hline 66 & 1027.2 & 1,6 & 141 & 1030,5 & 1,6 \\
\hline 67 & 1023.0 & 2,8 & 142 & 1001.2 & 5.3 \\
\hline 68 & 1069.3 & 2,4 & 143 & 1082.7 & 2,9 \\
\hline 69 & 1051,7 & 2,2 & 144 & 1062,0 & 1,8 \\
\hline 70 & 1191,6 & 6,8 & 145 & 1041.8 & 1,6 \\
\hline 71 & 1047,6 & 6,1 & 146 & 1020.0 & 3.5 \\
\hline 72 & 1125,1 & 5.2 & 147 & 1075,3 & 3.4 \\
\hline 73 & 992.5 & 9.1 & 148 & 1039.4 & 1,5 \\
\hline 74 & 1077,8 & 7.8 & 149 & 1073.5 & 3,0 \\
\hline 75 & 995.7 & 7,8 & 150 & 1072,0 & 1,4 \\
\hline
\end{tabular}

O desvio padrão percentual das cento e cinqüenta leituras médias. ou seja. a variação da sensibilidade do grupo foi determinada como sendo de $4.7 \%(1 \sigma)$. 


\subsection{Estudo da atenuação da capa de equilíbrio eletrônico}

Os perfis de dose relativa foram obtidos nas direçòes latero-lateral (eixo x) e crâniocaudal (eixo y) com relação ao sistema de coordenadas do campo de radiação (FIGs. 15 e 16), e foram normalizados a $3 \mathrm{~cm}$ do centro do campo. A absorção pelo TLD na capa de equilíbrio eletrônico pôde ser estimada em no máximo $7,1 \%$ na direção $x$ e $7.4 \%$ na direção y.

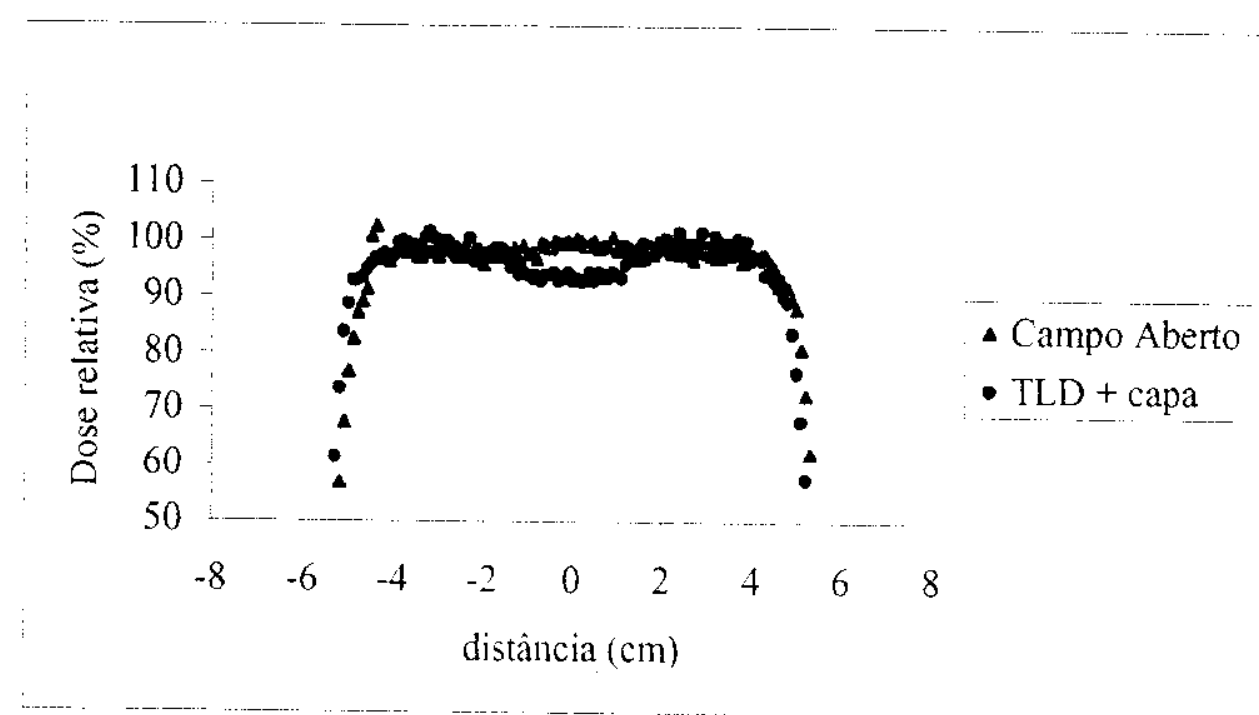

FIGURA 15 - Atenuação da dose produzida pela capa de equilibrio eletrônico. Os perfis foram obtidos na direção $\mathrm{x}$ do sistema de coordenadas do campo de radiação

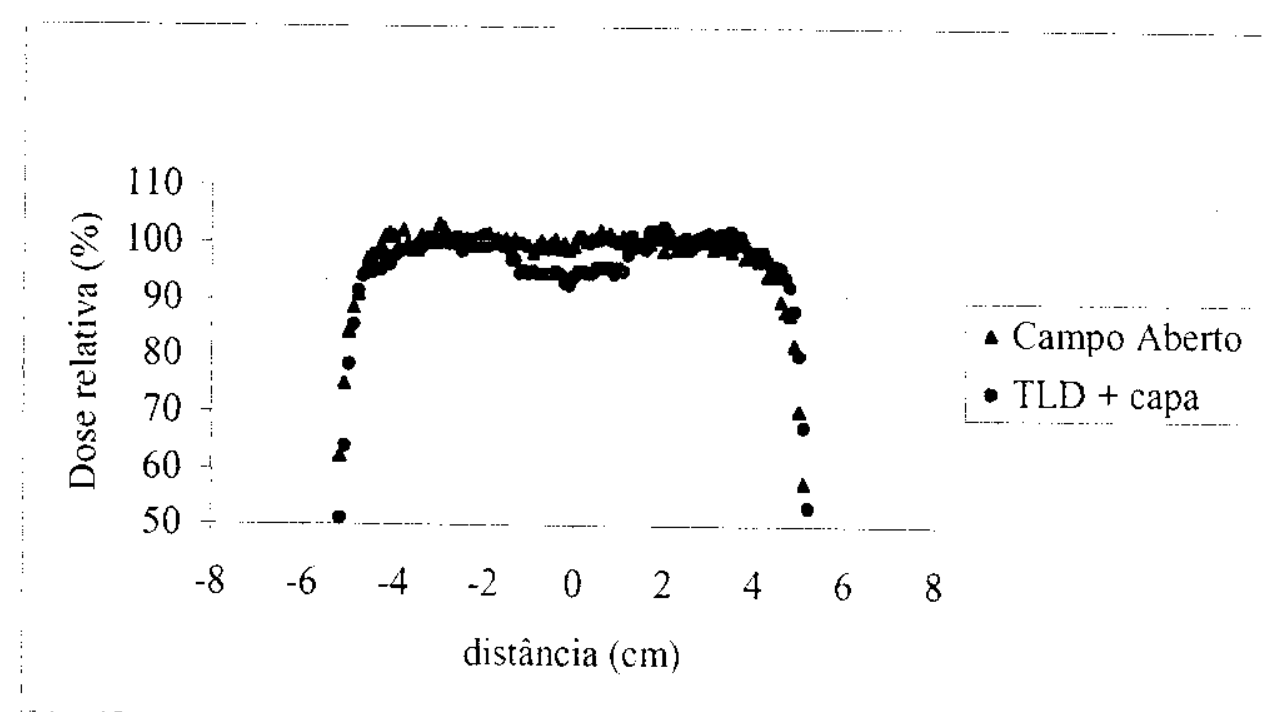

FIGURA 16 - Atenuação da dose produzida pela capa de equilibrio eletrônico. Os perfis foram obtidos na direção y do sistema de coordenadas do campo de radiação 
A capa de equilibrio eletrònico produz uma redução na variação máxima dos fatores de correção. Em geral. a capa de equilíbrio eletrônico pode melhorar a situação a um nível em que os fatores de correção podem ser ignorados.

O efeito de atenuação aumenta com o uso da capa. Entretanto, como o número de medidas que são realizadas em um mesmo paciente é pequeno. esse efeito não representa um problema.

\subsection{Calibração e fatores de correção}

Os fatores de calibração para medida de dose de entrada com a capa de equilibrio eletrônico. bem como os desvios padrão percentuais das três leituras das vinte e duas pastilhas calibradas estão apresentados na TAB. 8.

TABELA 8 - Fatores de calibração e desvios padrão percentuais das leituras dos TLDS calibrados

$\begin{array}{ccc}\text { TLD } & \mathrm{F}_{\text {cal }}(\mathrm{Gy} / \eta \mathrm{C}) & \sigma(\%) \\ \mathbf{3} & 0.1528 & 1.9 \\ \mathbf{4} & 0.1594 & 1.8 \\ \mathbf{8} & 0.1644 & 2.3 \\ \mathbf{1 2} & 0.1626 & 2.2 \\ \mathbf{1 3} & 0.1637 & 1.5 \\ \mathbf{1 4} & 0.1626 & 1.7 \\ \mathbf{1 5} & 0.1637 & 2.3 \\ \mathbf{1 6} & 0,1581 & 2.5 \\ \mathbf{1 8} & 0.1649 & 2.1 \\ \mathbf{1 9} & 0.1607 & 2.3 \\ \mathbf{3 3} & 0.1586 & 2.2 \\ \mathbf{3 6} & 0.1622 & 1.9 \\ \mathbf{6 0} & 0.1649 & 1.5 \\ \mathbf{6 5} & 0.1582 & 1.4 \\ \mathbf{6 6} & 0.1638 & 1.5 \\ \mathbf{8 4} & 0.1608 & 2.3 \\ \mathbf{1 0 7} & 0.1619 & 1.4\end{array}$




\begin{tabular}{lll}
114 & 0.1615 & 2.5 \\
126 & 0.1588 & 2.4 \\
132 & 0.1635 & 2.5 \\
141 & 0.1575 & 1.6 \\
148 & 0.1645 & 2.2 \\
\hline
\end{tabular}

O estudo da resposta TL em função da dose absorvida mostrou um comportamento linear para as doses fornecidas de até 2.27 Gy. Na TAB. 9 estão apresentados os valores correspondentes de dose. as leituras TL, o valor médio e o desvio padrão das cinco medidas dos nove grupos irradiados com 5, 25, 50.75, 100, 150. 200.250 e 300 UM cada. A curva de calibração está apresentada na FIG. 17.

TABELA 9 - Variação da resposta termoluminescente em função da dose absorvida para diferentes unidades monitoras fornecidas

\begin{tabular}{|c|c|c|c|c|c|c|c|c|c|}
\hline $\begin{array}{c}\text { UM } \\
\text { Dose (Gy) }\end{array}$ & $\stackrel{5}{5}$ & $\begin{array}{c}\mathbf{2 5} \\
0.192\end{array}$ & $\begin{array}{c}\mathbf{5 0} \\
0.381\end{array}$ & $\begin{array}{c}75 \\
0.570\end{array}$ & $\begin{array}{c}100 \\
0.759\end{array}$ & $\begin{array}{c}\mathbf{1 5 0} \\
1.137\end{array}$ & $\begin{array}{c}\mathbf{2 0 0} \\
1.502\end{array}$ & $\begin{array}{c}250 \\
1.893\end{array}$ & $\begin{array}{c}300 \\
2.270\end{array}$ \\
\hline \multirow{5}{*}{ 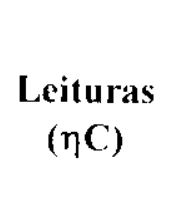 } & 34.7 & 146.4 & 281.0 & 428.9 & 547.1 & 833.3 & 1105.0 & 1411.0 & 1670.0 \\
\hline & 34,2 & 142.5 & 282,5 & 420,1 & 557.8 & 821.1 & 1114.0 & 1359.0 & 1631.0 \\
\hline & 33.2 & 139.5 & 271,7 & 413,4 & 548,2 & 826,4 & 1106.0 & 1401,0 & 1680.0 \\
\hline & 32.3 & 140,9 & 274,1 & 416.3 & 540.0 & 823.5 & 1096,0 & 1370.0 & 1672.0 \\
\hline & 32,4 & 141,0 & 276,9 & 408,8 & 548,9 & 823.2 & 1108,0 & 1384,0 & 1677.0 \\
\hline $\mathbf{L}_{\text {médilil }}$ & 33.4 & $1+2,1$ & 277,2 & 417,5 & 548.4 & 825,5 & 1105,8 & 1385 & 1666 \\
\hline$\sigma$ & 1,07 & 2.65 & 4.54 & 7,59 & 6.34 & 4.75 & 6.50 & 21,41 & 19.96 \\
\hline$\sigma(1 / 10)$ & 3.20 & 1.86 & 1.64 & 1.82 & 1,16 & 0.58 & 0.59 & 1.55 & 1.20 \\
\hline
\end{tabular}




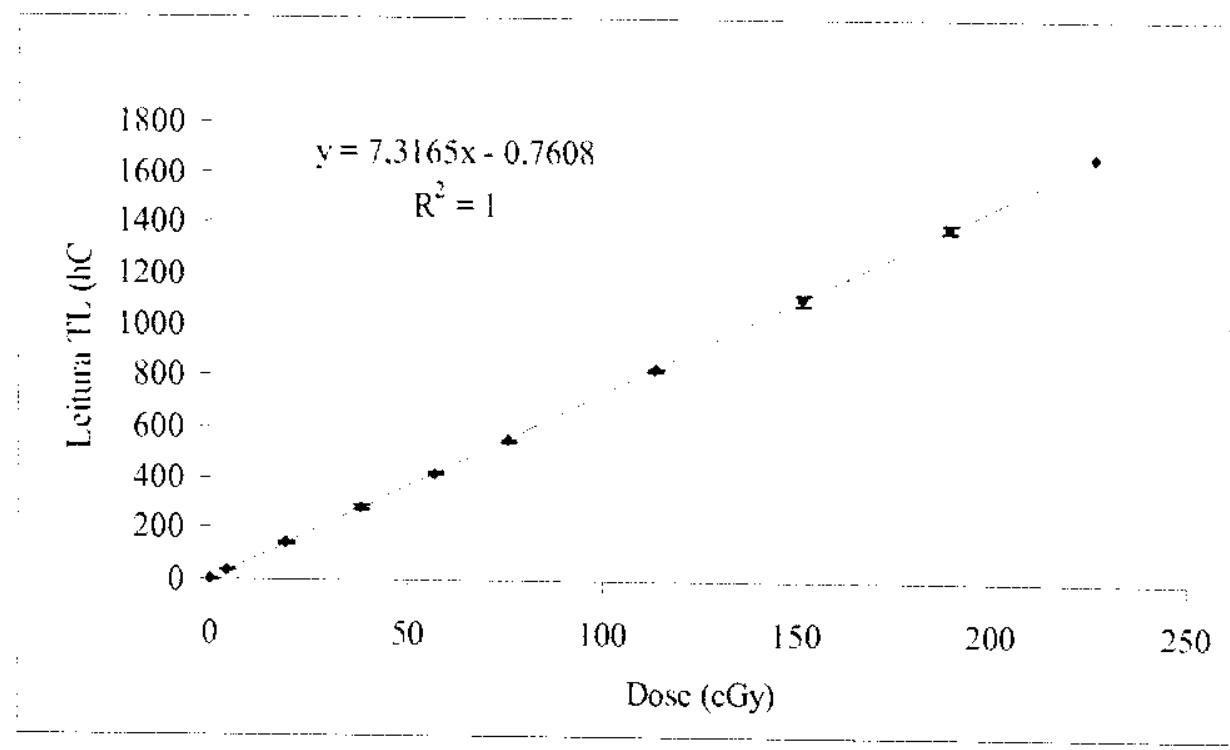

FIGURA 17 - Variação da resposta TL com a dose absorvida

Como o sinal do dosímetro TL é proporcional à fluência de elétrons na profundidade do volume sensível do dosímetro, a razão da leitura da câmara de ionização e da leitura do dosímetro depende do tamanho do campo. Para tamanhos de campos grandes, a contaminação do feixe primário devido aos elétrons e aos fótons de baixa energia, criados no cabeçote do acelerador linear, aumenta a dose na superficie e diminui a profundidade de dose máxima. Conseqüentemente, a espessura da capa de equilíbrio eletrônico, que é suficiente para assegurar equilíbrio eletrônico para tamanhos de campos grandes, pode não ser suficiente para tamanhos de campos menores. Nesses casos, a razão $\mathrm{L}_{C \mathrm{C}} / \mathrm{L}_{\mathrm{TLD}}$ apresentaria um comportamento nào linear em funçào do tamanho do campo, sendo necessário, então, aplicar um fator de correção para compensar a falta de equilibrio eletrônico.

Os fatores de correção para tamanhos de campos quadrados de lados $5,10,15,20$, 25 e $30 \mathrm{~cm}$ determinados para as duas unidades de tratamento estão apresentados na TAB. 10. O comportamento linear apresentado no gráfico da FIG. 18 evidencia que a espessura da capa de equilibrio eletrônico mostrou-se satisfatória para garantir o equilíbrio eletrônico para tamanhos de campos menores que $10 \times 10 \mathrm{~cm}^{2}$. 
TABELA 10 - Valores dos fatores de correção em função do tamanho de campo

\begin{tabular}{ccccccc}
\hline $\begin{array}{c}\text { Unidade } \\
\text { de } \\
\text { tratamento }\end{array}$ & $\begin{array}{c}\text { Lado do } \\
\text { campo }(\mathrm{cm})\end{array}$ & $\begin{array}{c}\mathrm{L}_{\text {media }}(\eta \mathrm{C}) \\
(\mathrm{CI})\end{array}$ & $\begin{array}{c}\mathrm{L}_{\text {media }}(\eta \mathrm{C}) \\
(\mathrm{TLD})\end{array}$ & $\mathrm{L}_{\mathrm{CI}} \mathrm{L}_{\mathrm{TLD}}$ & $\left(\mathrm{L}_{\mathrm{C}} / \mathrm{L}_{\mathrm{TLD}}\right)_{\mathrm{rel}}$ & $\mathrm{FC}$ \\
\hline \multirow{4}{*}{$\mathrm{MX}-2$} & 5 & 18,480 & 296,3 & 0,0624 & 0,0632 & 0,9864 \\
& 10 & $19,632^{*}$ & $310,5^{*}$ & 0,0632 & 0,0632 & 1,0000 \\
& 15 & 20,307 & 317,3 & 0,0640 & 0,0632 & 1,0122 \\
& 20 & 20,655 & 322,7 & 0,0640 & 0,0632 & 1,0123 \\
& 25 & 20,861 & 319,8 & 0,0652 & 0,0632 & 1,0317 \\
& 30 & 20,972 & 318,6 & 0.0658 & 0,0632 & 1,0411 \\
\hline \multirow{2}{*}{ KD-2 } & 5 & 18,485 & 291,2 & 0,0635 & 0,0646 & 0,9826 \\
& 10 & $19,630 *$ & $303,8^{*}$ & 0,0646 & 0,0646 & 1,0000 \\
& 15 & 20,317 & 310,2 & 0,0655 & 0,0646 & 1,0136 \\
& 20 & 20,650 & 314,7 & 0,0656 & 0,0646 & 1,0155 \\
& 25 & 20,865 & 314,4 & 0,0664 & 0,0646 & 1,0272 \\
& 30 & 20,970 & 310,0 & 0.0676 & 0,0646 & 1,0469 \\
\hline
\end{tabular}

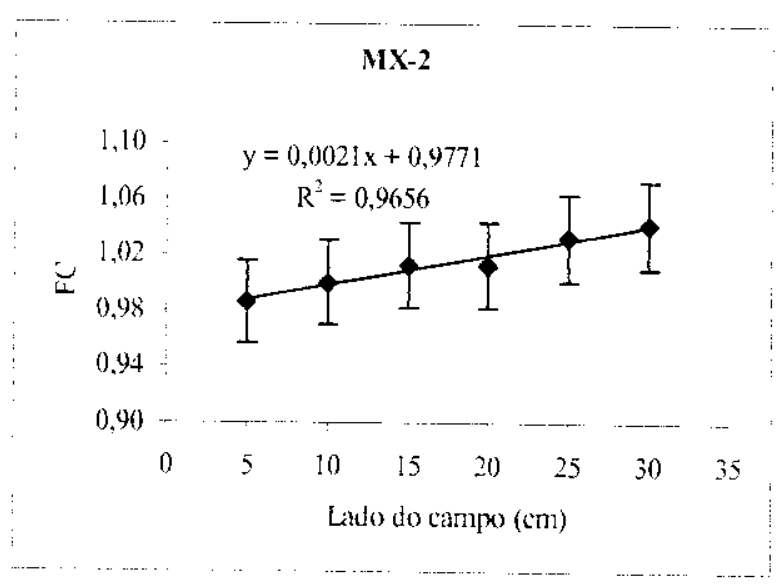

(a)

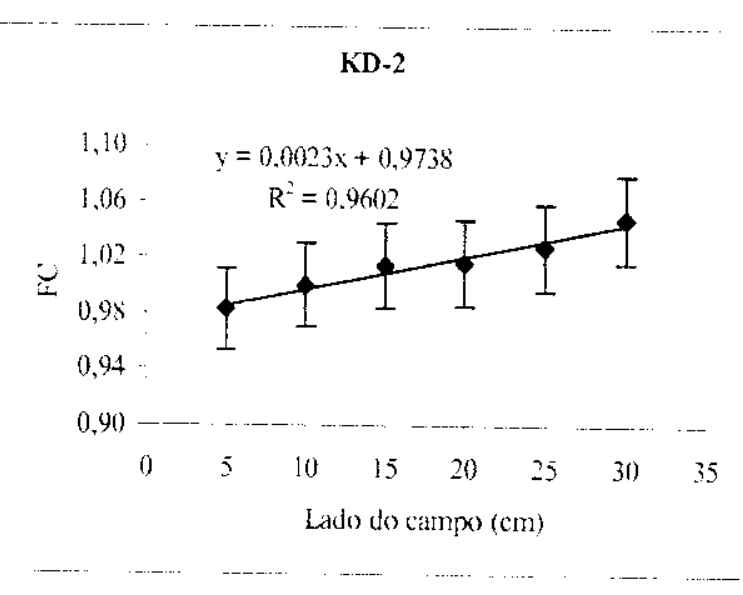

(b)

FIGURA 18 - Variação dos fatores de correçào em função do tamanho de campo para as unidades de tratamento MX-2 (a) e KD-2 (b)

Quando a DFS diminui, o número de elétrons e de fótons de baixa energia que contaminam o feixe primário é maior. Se a espessura da capa não é suficiente para garantir o equilíbrio eletrônico, a razão entre a leitura da CI e do TLD diminui. Os fatores de correção para distância fonte-superfície de $90,95,100,105$ e $110 \mathrm{~cm}$ determinados estão apresentados na TAB. 11 e na FIG. 19. Os resultados obtidos mostraram que a espessura da capa de equilibrio eletrônico utilizada foi adequada, uma vez que a razão $L_{C I} / L_{T L D}$ aumentou quando o valor da DFS foi reduzido de 100 para 95 e $90 \mathrm{~cm}$. 
TABELA 11 - Valores dos fatores de correçào em função da distância fonte-superfície

\begin{tabular}{|c|c|c|c|c|c|c|}
\hline $\begin{array}{l}\text { Unidade de } \\
\text { tratamento }\end{array}$ & $\operatorname{DFS}(\mathrm{cm})$ & $\begin{array}{c}L_{\text {media }}(\eta \mathrm{C}) \\
(\mathrm{CI}) \\
\end{array}$ & $\begin{array}{c}\mathrm{L}_{\text {média }}(\eta \mathrm{C}) \\
(\mathrm{TLD}) \\
\end{array}$ & $\mathrm{L}_{C I} \mathrm{~L}_{\text {TLD }}$ & $\left(\mathrm{L}_{\mathrm{CV}} / \mathrm{L}_{\mathrm{TLD}}\right)_{\mathrm{Tef}}$ & $\mathrm{FC}$ \\
\hline \multirow{5}{*}{$M X-2$} & 90 & 23,90 & 367,2 & 0,0651 & 0,0634 & 1,0273 \\
\hline & 95 & 21,43 & 330,6 & 0,0648 & 0,0634 & 1,0231 \\
\hline & 100 & $19,33^{*}$ & $305,1^{*}$ & 0.0634 & 0,0634 & 1,0000 \\
\hline & 105 & 17,50 & 281,5 & 0,0637 & 0,0634 & 1,0054 \\
\hline & 110 & 15,94 & 253,0 & 0.0630 & 0,0634 & 0,9944 \\
\hline \multirow{5}{*}{ KD-2 } & 90 & 23,88 & 365,5 & 0,0653 & 0,0636 & 1,0277 \\
\hline & 95 & 21.41 & 334,1 & 0,0641 & 0,0636 & 1,0078 \\
\hline & 100 & $19,32 *$ & $303,8^{*}$ & 0,0636 & 0,0636 & 1,0000 \\
\hline & 105 & 17,51 & 272,2 & 0,0637 & 0,0636 & 1,0018 \\
\hline & 110 & 15,95 & 249,4 & 0.0639 & 0,0636 & 1,0057 \\
\hline
\end{tabular}

*Valores de referencia

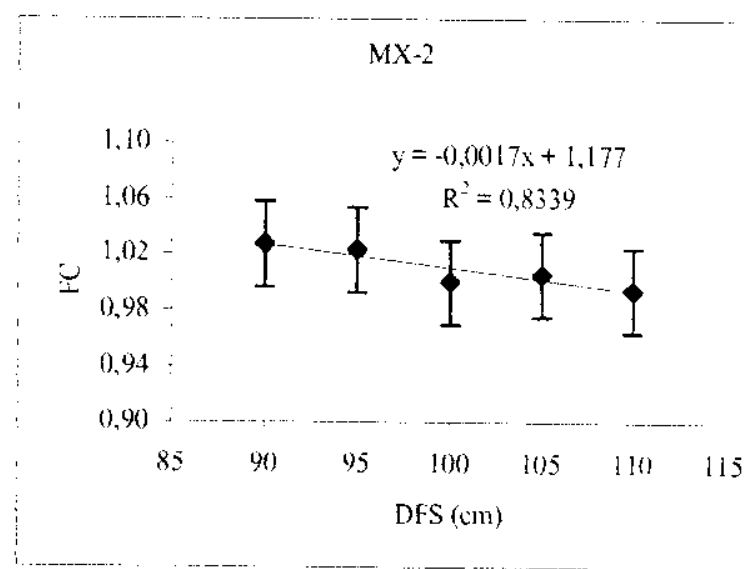

(a)

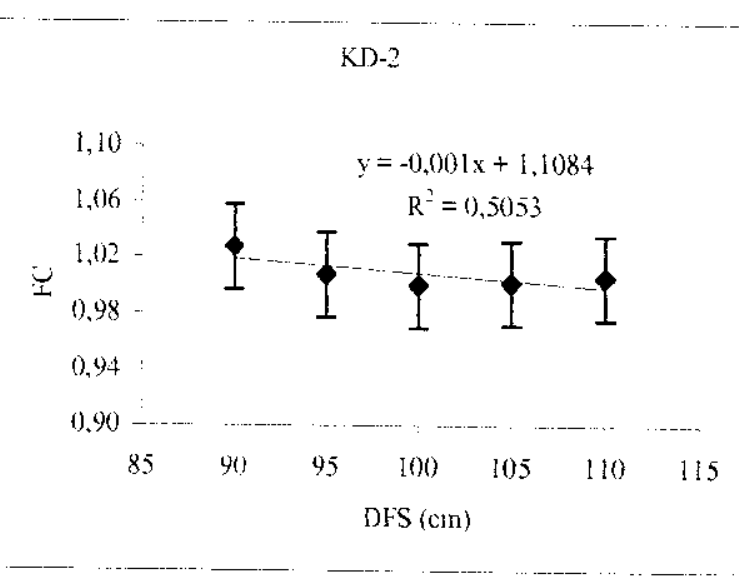

(b)

FIGURA 19 - Variação dos fatores de correção em função da DFS para as unidades de tratamento $\mathrm{MX}-2$ (a) e KD-2 (b)

Na TAB. 12 e na FIG. 20 estão apresentados, respectivamente, os valores e o comportamento dos fatores de correção em função do ângulo de incidência do feixe. Nesse caso também, a espessura da capa mostrou-se adequada para garantir o equilíbrio de particulas carregadas nos diferentes ângulos de incidência do feixe analisados. 
TABELA 12 - Valores dos fatores de correção em função do ângulo de incidência do feixe

\begin{tabular}{ccccccc}
\hline $\begin{array}{l}\text { Unidade de } \\
\text { tratamento }\end{array}$ & $\begin{array}{c}\text { Angulo de } \\
\text { incidencia } \\
\text { (grau) }\end{array}$ & $\begin{array}{c}\mathrm{L}_{\text {media }}(\eta \mathrm{C}) \\
(\mathrm{CI})\end{array}$ & $\begin{array}{c}\mathrm{L}_{\text {midia }}(\eta \mathrm{C}) \\
\text { (TLD) }\end{array}$ & $\mathrm{L}_{\mathrm{C} /} / \mathrm{L}_{\mathrm{TLD}}$ & $\left(\mathrm{L}_{\mathrm{C} /} / \mathrm{L}_{\mathrm{TLD}}\right)_{\mathrm{ret}}$ & $\mathrm{FC}$ \\
\hline \multirow{3}{*}{$\mathrm{MX}-2$} & 45 & 19,441 & 300,6 & 0,0647 & 0,0632 & 1,0229 \\
& 50 & 19,304 & 301,0 & 0,0641 & 0,0632 & 1,0143 \\
& 55 & 19,103 & 299,8 & 0,0637 & 0,0632 & 1,0078 \\
& 60 & 18,781 & 301,3 & 0,0623 & 0,0632 & 0,9859 \\
$\mathrm{KD}-2$ & 45 & 19,442 & 306,0 & 0,0635 & 0,0646 & 0,9833 \\
& 50 & 19,303 & 304,0 & 0,0635 & 0,0646 & 0,9827 \\
& 55 & 19,105 & 303,2 & 0,0630 & 0,0646 & 0,9752 \\
& 60 & 18,783 & 299,2 & 0,0628 & 0,0646 & 0,9715 \\
\hline
\end{tabular}

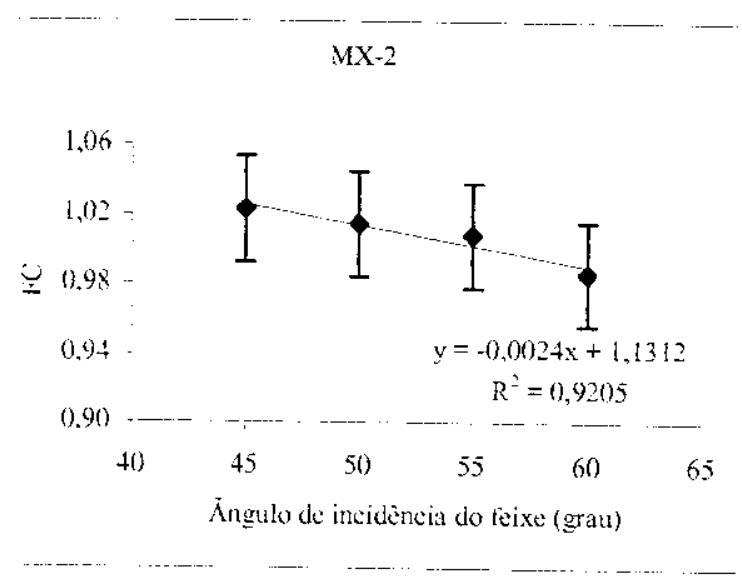

(a)

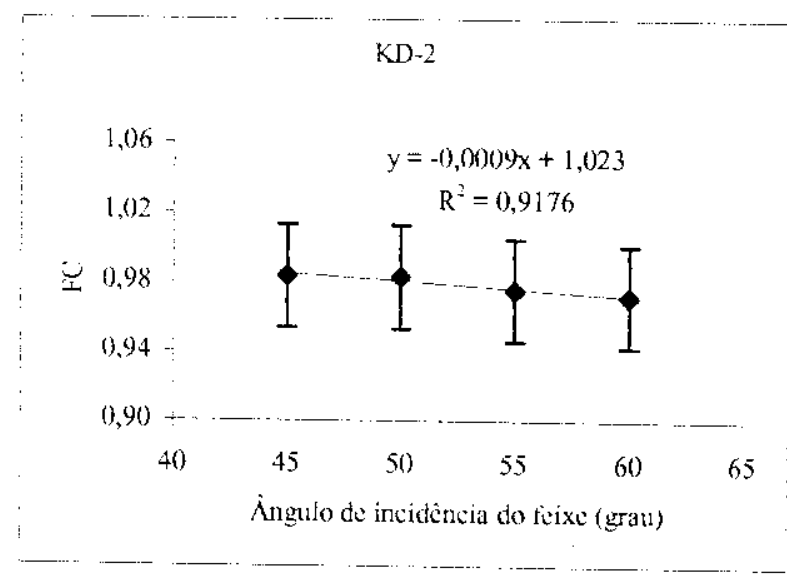

(b)

FIGURA 20 - Variação dos fatores de correção em função do ângulo de incidência do feixe para as unidades de tratamento MX-2 (a) e KD-2 (b)

Quando dispositivos modificadores do feixe como os filtros físicos em cunha são usados, não apenas a contaminação do feixe, mas também a taxa de dose é modificada e um fator de correção pode ser necessário. Os fatores de correção para os diferentes filtros físicos de $15^{\circ}, 30^{\prime \prime}$ e $45^{\circ}$ determinados estào apresentados na TAB 13.

TABELA 13 - Valores dos fatores de correção em função do ângulo do filtro físico para o tamanho de campo de referência

\begin{tabular}{ccc}
\hline Unidade de tratamento & Filtro & FC \\
\hline \multirow{2}{*}{ MX-2 } & $15^{\mathrm{o}}$ & 1,0407 \\
& $30^{\mathrm{o}}$ & 0,9926 \\
& $45^{\mathrm{o}}$ & 0,9455 \\
\hline \multirow{3}{*}{ KD-2 } & $15^{\mathrm{o}}$ & 1,0399 \\
& $30^{\mathrm{o}}$ & 1,0048 \\
& $45^{\mathrm{o}}$ & 0,9837 \\
\hline
\end{tabular}


Os vários testes da resposta TLD nas diferentes geometrias do feixe mostraran que a capa de equilibrio eletrônico utilizada foi confeccionada com uma espessura adequada e com forma apropriada para garantir que fatores de correção devido a insuficiência de material não fôssem necessários.

Não foram empregados fatores para corrigir o desvanecimento do sinal TL, pois as leituras (obtidas até $72 \mathrm{~h}$ após a irradiação) foram realizadas com um tratamento térmico pré-lcitura e somente os picos com meias-vidas longas foram integrados durante a aquisição. A dependência energética não foi considerada. uma vez que os TLDs caracterizados se destinaram a dosimetria em tratamentos utilizando uma única energia de fótons.

\subsection{Medidas em objetos simuladores}

A TAB. 14 apresenta a razão da dose determinada com TLD e o valor obtido pelo sistema de planejamento por meio do recurso de dose pontual.

TABELA 14 - Comparação entre a dose de entrada medida com o dosímetro TL e a dose calculada pelo sistema de planejamento

\begin{tabular}{cccc}
\hline Medida & $\mathrm{D}_{\text {TPS }(\mathrm{Gy})}$ & $\mathrm{D}_{\text {TLD }}(\mathrm{Gy})$ & Razão \\
\hline 1 & 0.986 & 0,985 & 0.999 \\
2 & 0,986 & 0,984 & 0.998 \\
3 & 0.706 & 0,711 & 1.007 \\
4 & 0.541 & 0.535 & 0,989 \\
5 & 0.488 & 0,493 & 1,010 \\
6 & 1.019 & 1.022 & 1,003 \\
7 & 1,231 & 1,225 & 0,995 \\
8 & 0,912 & 0,905 & 0.992 \\
9 & 0.682 & 0,691 & 1,013 \\
10 & 0.583 & 0.571 & 0,979 \\
11 & 0.921 & 0.911 & 0.989 \\
12 & 0.685 & 0.697 & 1.018 \\
13 & 0.592 & 0.601 & 1,015 \\
14 & 0.651 & 0.641 & 0,985 \\
15 & 0.864 & 0,877 & 1,015 \\
\hline
\end{tabular}

A exatidão da determinação da dose com TLD para medida da dose de entrada foi . avaliada em 1.001 com um desvio padrão de 1.2\%. Os valores de dose de entrada medidos durante a verificação do sistema dosimétrico apresentaram concordância dentro de $\pm 5 \%$ 
(máxima de $2,1 \%$ e média de $0.1 \%$ ). com relação à dose de entrada gerada pelo TPS. indicando um bom desempenho do sistema considerado.

\subsection{Medidas in vivo}

Na TAB. 15 estão apresentados os parâmetros relevantes do tratamento para o campo interno para as 5 pacientes envolvidas no estudo. Esses parâmetros são: localização do tratamento (mama direita ou esquerda); distância fonte-superfície: ângulo de incidência do reixe de irradiação; ângulo do filtro físico; ângulo da mesa de tratamento: ângulo do colimador; tamanho de campo; tamanho do campo quadrado equivalente ao tamanho de campo empregado no tratamento; peso relativo do campo interno: contribuição do campo interno para a dose total planejada no ponto de medida: dose por fração: dose total; isodose de prescrição do tratamento: isodose no ponto de medida determinado por meio do recurso de dose pontual; e ponto de normalização da dose.

TABELA 15 - Parâmetros de tratamento do campo interno das cinco pacientes

\begin{tabular}{|c|c|c|c|c|c|}
\hline Paciente: & 1 & 2 & 3 & 4 & 5 \\
\hline Mama: & esquerda & direita & esquerda & esquerda & direita \\
\hline DFS $(\mathrm{cm})$ : & 91.8 & $88.3 \mathrm{~cm}$ & 89.7 & 91.4 & 90.4 \\
\hline $\begin{array}{l}\text { Angulo de } \\
\text { incidencia: }\end{array}$ & $292^{\circ}$ & $60^{\circ}$ & $305^{\circ}$ & $301^{\circ}$ & $60^{\circ}$ \\
\hline Filtro: & $15^{\circ}$ & $30^{\circ}$ & $30^{\circ}$ & $15^{\circ}$ & $15^{\circ}$ \\
\hline Mesa: & $0^{\circ}$ & $0^{\circ}$ & $0^{\circ}$ & $354^{\circ}$ & $6^{\circ}$ \\
\hline $\begin{array}{l}\text { Colimador: } \\
\text { Campo: }\end{array}$ & $90^{\circ}$ & $180^{\circ}$ & $10^{\circ}$ & $3^{\circ}$ & $357^{\circ}$ \\
\hline$X(\mathrm{~cm})$ & 16,0 & 10.6 & 9.6 & 13.9 & 12.2 \\
\hline$Y(\mathrm{~cm})$ & 7,5 & 21,7 & 20.9 & 21.6 & 16.8 \\
\hline$X 1(\mathrm{~cm})$ & 8.0 & 1.5 & 0.0 & 4.8 & 8.7 \\
\hline $\mathrm{X} 2(\mathrm{~cm})$ & 8,0 & 9.0 & 9.6 & 9.1 & 3.5 \\
\hline $\mathrm{Yl}(\mathrm{cm})$ & 7.5 & 11,2 & 10.3 & 11.6 & 7.2 \\
\hline $\mathrm{Y} 2(\mathrm{~cm})$ & 0,0 & 10,5 & 10.6 & 10.0 & 9.6 \\
\hline $\begin{array}{l}\text { Quadrado } \\
\text { equivalente: }\end{array}$ & 10.2 & 14,2 & 13.2 & 16.9 & 14.1 \\
\hline Peso: & 1,00 & 0.85 & 1.00 & 1.00 & 1.00 \\
\hline Contribuição: & $0.541 \pm 0.005$ & $0.708 \pm 0.007$ & $0.710 \pm 0.003$ & $0,633 \pm 0,005$ & $0.675 \pm 0.004$ \\
\hline $\begin{array}{l}\text { Dosé/traçao } \\
\text { (Gy): }\end{array}$ & 2.00 & 2.0 & 2.0 & 1.80 & 2,00 \\
\hline $\begin{array}{l}\text { Dose Total } \\
\text { (Gy): }\end{array}$ & 50.0 & 50.0 & 50.0 & 50.4 & 50.0 \\
\hline $\begin{array}{l}\text { Isodose de } \\
\text { prescrição: }\end{array}$ & $95,0 \%$ & $95.0 \%$ & $95.0 \%$ & $97.0 \%$ & $95.0 \%$ \\
\hline
\end{tabular}


Isodose no

ponto de

$103 \%$

$95 \%$

$98 \%$

$98 \%$

$101 \%$

medida:

Ponto de

normalização:

$100.0 \% \quad 100.0 \%$

$100.0 \%$

$100.0 \%$

$100.0 \%$

Na TAB. 16 estão apresentados os fatores de correção, com os respectivos valores de incertezas associadas, aplicados no cálculo da dose de entrada com TLD às cinco pacientes envolvidas.

TABELA 16 - Fatores de Correção aplicados às medidas de dose de entrada in vivo com TLD nas cinco pacientes

\begin{tabular}{|c|c|c|c|c|c|}
\hline \multirow{2}{*}{ FC } & \multicolumn{5}{|c|}{ PACIENTE } \\
\hline & 1 & 2 & 3 & 4 & 5 \\
\hline $\begin{array}{c}F C_{\text {DFS }} \\
\text { (distância } \\
\text { fonte- } \\
\text { superfície) }\end{array}$ & $\begin{array}{c}1.0209 \\
\pm 0.0306\end{array}$ & $\begin{array}{c}1.0201 \\
\pm 0.0306\end{array}$ & $\begin{array}{c}1.0187 \\
\pm 0.0306\end{array}$ & $\begin{array}{r}1.0170 \\
\pm 0.0305\end{array}$ & $\begin{array}{r}1.0180 \\
\pm 0.0305\end{array}$ \\
\hline $\begin{array}{c}\mathrm{FC}_{\text {ângulo }} \\
\text { (ângulo de } \\
\text { incidência do } \\
\text { feixe) }\end{array}$ & $\begin{array}{c}0,9680 \\
\pm 0.0290\end{array}$ & $\begin{array}{c}0,9690 \\
\pm 0,0290\end{array}$ & $\begin{array}{c}0.9735 \\
\pm 0.0292\end{array}$ & $\begin{array}{c}0,9699 \\
\pm 0.0290\end{array}$ & $\begin{array}{r}0.9690 \\
\pm 0.0290\end{array}$ \\
\hline $\begin{array}{c}\mathrm{FC}_{\text {filtro }} \\
\text { (filtro físico) }\end{array}$ & $\begin{array}{c}1,0477 \\
\pm 0,0314\end{array}$ & $\begin{array}{r}1.0048 \\
\pm 0.0301\end{array}$ & $\begin{array}{r}1.0048 \\
\pm 0,0301\end{array}$ & $\begin{array}{r}1.0399 \\
\pm 0.0312\end{array}$ & $\begin{array}{r}1.0399 \\
\pm 0.0312\end{array}$ \\
\hline $\begin{array}{c}F_{\text {campo }} \\
\text { (abertura do } \\
\text { colimador) }\end{array}$ & $\begin{array}{c}0.9985 \\
\pm 0.0299\end{array}$ & $\begin{aligned} & 1.0065 \\
\pm & 0.0302\end{aligned}$ & $\begin{array}{c}1.0042 \\
\pm 0.0301\end{array}$ & $\begin{array}{c}1.0127 \\
\pm 0.0304\end{array}$ & $\begin{array}{r}1.0062 \\
\pm 0.0302\end{array}$ \\
\hline
\end{tabular}

As TABs. 17 a 20 apresentam a razão dos valores das doses de entrada medidas com dosímetro TL (D $\mathrm{TI}_{\mathrm{TI}}$ ) e das doses calculadas por meio do sistema de planejamento (D das três medidas. A paciente 3 teve seu tratamento interrompido e a paciente 5 teve alta antes da obtenção da terceira medida. por isso os valores das doses medidas e calculadas para estas pacientes não aparecem nas TABs. 19 e 21 . respectivamente. 
TABELA 17 - Comparação entre os valores das doses medidas (TLD) e calculadas (TPS) nos très dias consecutivos de medidas - paciente 1

\begin{tabular}{|c|c|c|c|}
\hline Medida & $\mathrm{D}_{T ! . D}(\mathrm{~Gy})$ & $\mathrm{D}_{\text {Tl's }}(\mathrm{Gy})$ & Razão \\
\hline $1^{i 1}$ & $1.228 \pm 0.052$ & $1.173 \pm 0.023$ & 1.047 \\
\hline $2^{: 1}$ & $1,187 \pm 0.049$ & $1,173 \pm 0,023$ & 1,012 \\
\hline $3^{a}$ & $1,209 \pm 0,051$ & $1,173 \pm 0.023$ & 1.031 \\
\hline Média & $1.208 \pm 0.051$ & $1,173 \pm 0,023$ & $1.030 \pm 0,017$ \\
\hline
\end{tabular}

TABEL A 18 - Comparação entre os valores das doses medidas (TLD) e calculadas (TPS) nos três dias consecutivos de medidas - paciente 2

\begin{tabular}{cccc}
\hline Medida & $\mathrm{D}_{\text {TLD }}(\mathrm{Gy})$ & $\mathrm{D}_{\text {TPS }}(\mathrm{Gy})$ & Razão \\
\hline $1^{\mathrm{i}}$ & $1.468 \pm 0,062$ & $1.416 \pm 0,028$ & 1.037 \\
$2^{\mathrm{i}}$ & $1.391 \pm 0,058$ & $1,416 \pm 0,028$ & 0.983 \\
$3^{\mathrm{a}}$ & $1.448 \pm 0.061$ & $1.416 \pm 0,028$ & 1,022 \\
Média & $1.436 \pm 0,060$ & $1.416 \pm 0,028$ & $1,014 \pm 0.028$ \\
\hline
\end{tabular}

TABELA 19 - Comparação entre os valores das doses medidas (TLD) e calculadas (TPS) nos três dias consecutivos de medidas - paciente 3

\begin{tabular}{cccc}
\hline Medida & $\mathrm{D}_{\text {T!. }}(\mathrm{Gy})$ & $\mathrm{D}_{\operatorname{TPS}}(\mathrm{Gy})$ & Razão \\
\hline $1^{\mathrm{it}}$ & $1.504 \pm 0,063$ & $1.463 \pm 0.029$ & 1,028 \\
$2^{:}$ & $1.448 \pm 0,061$ & $1.463 \pm 0.029$ & 0,990 \\
Média & $1.476 \pm 0.062$ & $1.463 \pm 0,029$ & $1.009 \pm 0.027$ \\
\hline
\end{tabular}

TABELA 20 - Comparação entre os valores das doses medidas (TLD) e calculadas (TPS) nos três dias consecutivos de medidas - paciente 4

\begin{tabular}{cccc}
\hline Medida & $\mathrm{D}_{\text {Tl. }}(\mathrm{Gy})$ & $\mathrm{D}_{\text {TPS }}(\mathrm{Gy})$ & Razão \\
\hline $1^{\mathrm{it}}$ & $1.154 \pm 0,048$ & $1.152 \pm 0.023$ & 1.002 \\
$2^{:}$ & $1.193 \pm 0.050$ & $1.152 \pm 0,023$ & 1.036 \\
$3^{\mathrm{i}}$ & $1.144 \pm 0,048$ & $1.152 \pm 0.023$ & 0.993 \\
Média & $1.164 \pm 0,049$ & $1.152 \pm 0,023$ & $1,010 \pm 0,023$ \\
\hline
\end{tabular}


TABELA 21 - Comparação entre os valores das doses medidas (TLD) e calculadas (TPS) nos três dias consecutivos de medidas - paciente 5

\begin{tabular}{cccc}
\hline Medida & $\mathrm{D}_{\text {T1.D }}(\mathrm{Gy})$ & $\mathrm{D}_{\text {TISs }}(\mathrm{Gy})$ & Razào \\
\hline $1^{\mathrm{a}}$ & $1.413 \pm 0,059$ & $1.435 \pm 0.028$ & 0.985 \\
$2^{\mathrm{a}}$ & $1.395 \pm 0,059$ & $1.435 \pm 0,028$ & 0.972 \\
Média & $1.404 \pm 0.059$ & $1.435 \pm 0,028$ & $0.978 \pm 0.009$ \\
\hline
\end{tabular}

A precisão média durante a dosimetria in vivo, obtida das determinações de dose realizadas nas 5 pacientes. foi de $1.011 \mathrm{com}$ um desvio padrão de $2.4 \%$.

O desvio padrão relativamente pequeno $(2.4 \%)$ dos resultados das medidas de dose de entrada. em comparação com resultados apresentados na revisão da literatura. deve-se à excelente estabilidade do equipamento de tratamento, ao sistema automático de verificação e à boa exatidão no ajuste diário do tratamento. Embora não tenha sido detectado nenhum grande erro na liberação da dose nos casos estudados, a literatura mostra que o emprego periódico da dosimetria in vivo é útil como uma verificação das várias técnicas de tratamento, que podem ser avaliadas e melhoradas. Grandes erros podem ser detectados e as suas fontes podem ser identificadas e corrigidas, diminuindo a incerteza na dose total fornecida a cada paciente.

\subsection{Estimativa das incertezas das medidas}

\subsubsection{Precisão individual do TLD}

A precisão intrínseca do dosímetro é a reprodutibilidade de um dado material $\mathrm{TL}$. associada com um dado sistema de leitura. É fortemente dependente da qualidade do material TL, usado, das características da leitura, do modo como o ciclo de aquecimento $\mathfrak{e}$ aquecimento foi definido, da pureza do gás de nitrogênio que circula no ambiente da prancheta de leitura, etc.

A incerteza das leituras individuais dos TLDs pôde ser estimada a partir da variação das leituras do conjunto de TLD irradiado com a mesma dose e lidos na mesma sessão. Os 22 TLDs pré-selecionados e empregados na medida de dose de entrada apresentaram precisão individual igual ou melhor que $\pm 3,0 \%$. Esse desvio representa toda a incerteza do processo de calibração. 


\subsubsection{Incerteza na determinação dos fatores de calibração e de correção}

A incerteza na determinação tanto dos fatores de calibração quanto dos fatores de correção dos TLDs é estimada pela raiz quadrada da soma dos quadrados das incertezas relativas de cada grandeza de entrada envolvida (a leitura da câmara de ionização e do dosímetro TL ). A incerteza associada às leituras com a câmara de ionização foi estimada em $0,1 \%$. Logo, a incerteza na determinação dos fatores de calibração e de correção é de $3.0 \%$.

\subsubsection{Incerteza na determinação da dose absorvida medida (TLD)}

A exatidão global das medidas é determinada por meio das incertezas combinadas da leitura TL e dos fatores de calibração. Com base nas incertezas estimadas dessas grandezas. a incerteza teórica na dose de entrada obtida pela combinação quadrática das incertezas mencionadas é de $4,2 \%$.

\subsubsection{Incerteza na determinação da dose absorvida esperada (TPS)}

A incerteza na determinação da dose absorvida determinada por meio do sistema de planejamento do tratamento é atribuida à falta de precisão na localização exata do ponto de dose de entrada por meio do recurso disponível do sistema de planejamento. A incerteza máxima determinada na localização do ponto de dose de entrada nas cinco medidas in vivo foi de $2,0 \%$. 


\section{CONClusões}

A dosimetria termoluminescente é uma dosimetria relativa. portanto. a exatidão alcançada depende de vários parâmetros tais como a reprodutibilidade da leitura TL e técnicas de calibração. Uma boa precisão em dosimetria in vivo pode ser alcançada somente quando os fatores de correção para cada parâmetro que influencia a resposta TL são cuidadosamente determinados e aplicados para converter o sinal TL em dose absorvida.

O método apresentado mostrou-se viável para o controle da dose de entrada no tratamento de câncer de mama. podendo ser aplicado a tratamentos de outras regioies anatômicas e que envolvam campos convencionais. 


\section{REFERÊNCIAS BIBLIOGRÁFICAS}

1 ASSOCIAÇÃO BRASILEIRA DE NORMAS TÉCNICAS. Guia para a expressĩo da incertéa de mediç̧ăo. Rio de Janeiro: ABNT, INMETRO. SBM. 1998.

2 BANJADE. D. P.: ALOYSIUS, R. T.; NG B. S.. XAVIER S.; TAJUDDIN. A. A.: SHUKKI. A. Entrance dose measurement: A simple and reliable technique. Med. Dosim.. v. 28. n. 2. p. 73-78, 2003.

3 BOOTH. L. F.: JOHNSON, T. L.; ATTIX, F. H. Lithium fluoride glow-peak growth due to annealing. Heath Phys.. v. 23. p. 137-142. 1972.

4 CAMERON, J.; SUNTHARALINGAM, N.: KENNY, G. Thermoluminescence Dosimetry, University of Wisconsin Press, Madison. 1968.

5 DA ROSA. L. A. R. Dosimetria termoluminescente aplicada à física médica. Instituto de Radioproteção e Dosimetria, IRD. Rio de Janeiro, 2000.

6 ESSERS. M.; MIJNHEER. B. J. In vivo dosimetry during external photon beam radiotherapy. Int. J. Rad. Onc. Biol. Phys.. v. 43. n.2, p. 245-259, 1999.

7 HAMERS, H. P.: JOHANSSON. K. A.; VENSELAAR. J. L. M.; DE BROUWER, P.; HANSSON, U.: MOUDI. C. Entrance and exit TL-dosimetry in the conservative treatment of breast cancer: a pilot study for the EORTC-Radiotherapy Cooperative Group. Radiother. Oncol., v. 22, p. 280-284. 1991.

8 HERBERT. C. E.: MARTIN. A. E.; JOSEPH, D. J. Feasible measurement errors when undertaking in vivo dosimetry during external beam radiotherapy of the breast. Med. Dosim.. v. 28, n. 1. p. 45-48, 2003.

9 HEUKELOM. S.; LANSON. J. H.; MIJNHEER. B. J. Comparison of entrance and exit dose measurements using ionization chambers and silicon diodes. Phys. Med. Biol., v. 36. p. 47-59, 1991 .

10 HEUKELOM. S.: LANSON, J. H.: VAN TIENHOVEN. G.: MIJNHEER. B. J. In vivo dosimetry during tangential breast treatment. Radiother. Oncol.. v. 22. p. 269-279. 1991.

11 HUYSKENS, D.; BOGAERTS. R.; VERSTRAETE, J.: LOOF. M.: NYSTRON. H.: FIORINO, C.; BROGGI, S.; JORNET, N.; RIBAS, M.: THWAITES. D. I. Practical guidelines for the implementation of in vivo dosimetry with diodes in external radiotherapy with photon beams (entrance dose). ESTRO. Booklet Nr 5. 2001.

12 INTERNATIONAL COMMISSION ON RADIATION UNITS AND MIASUREMENTS. Radiation dosimetry: electron beams with initial energies between 1 a $50 \mathrm{MeV}$. ICRU Report 35. 1984.

13 INTERNATIONAI COMMISSION ON RADIATION UNITS AND MEASUREMENTS. Determination of Absorbed Dose in a Patient Irradiated by 
Beams of X or Gamma Rays in Radiotherapy Procedures. ICRU Report 24. ICRU: Bethesda. 62 p., 1976.

14 JORDAN, T. J. Megavoltage X-ray beams: 2-50 MV Central axis depth dose data for use in radiotherapy. Br. J. Radiol., supplement 25, p. 62-110, 1996.

15 KRON. T., SCHNEIDER M., MURRAY A. AND MAMEGHAN H. Clinical thermoluminescence dosimetry: How do expectations and results compare? Radiother. Oncol., v. 26, p. 151-161, 1993-b.

16 I.EUNENS. G.; VAN DAM. J.; DUTREIX, A.; VAN DER SCHUEREN. E. Importance of in vivo dosimetry as part of a quality assurance program in tangencial breast treatments. Int. J. Rad. Onc. Biol. Phys., v. 28, p. 285-296, 1993.

17 LEUNENS, G. : VERSTRAETE, J. : VAN DEN BOGAERT. W. et al. Human errors in data transfer during the preparation and delivery of radiation treatment affecting the final result. "Garbage in garbage out." Radiother. Oncol., v. 23, p. 217-222, 1992.

18 LEUNENS, G.: VERSTRAETE, J.; VAN DAM, J.; DUTREIX, A.; VAN DER SCHUEREN, E. In vivo dosimetry for tangencial breast irradiation: role of the equipment in the accuracy of dose delivery. Radiother. Oncol., v. 22, p. 285-289. 1991.

19 LEUNENS, G.; VAN DAM, J.; DUTREIX. A.; VAN DER SCHUEREN, E. Quality assurance in radiotherapy by in vivo dosimetry. 2. Determination of the target absorbed dose. Radiother. Oncol., v. 19, p. 73-87. 1990.

20 LEUNENS. G.: VAN DAM. J.; DUTREIX. A.; VAN DER SCHUEREN, E. Quality assurance in radiotherapy by in vivo dosimetry. 1. Entrance dose measurements, a reliable procedure. Radiother. Oncol.. v. 17. p. 141-151, 1990.

21 LINSKOUG. B. AND LUNDBERG. L. "Clinical applications of thermoluminescent doismetry". Thermoluminescence and Thermoluminescent Dosimetry. By Y. Horowitz.. CRC Press, Boca Raton, Florida, p. 49-132. 1984.

22 I.ONCOL. T. H.: GREFFE. J. L.; VYNCKIER, S.: SCAL.LIET, P. Entrance and exit dose measurements with semiconductors and thermoluminescent dosemeters: a comparison of methods and in vivo results. Racliother. Oncol. v. 41, p. 179-187. 1996.

23 MACKINLAY. A. F. Thermoluminescence Dosimetry. Medical Physics Handbook 5. Adam Hilger, Bristol, UK. 1981.

24 MAYLES, W. P. M.: HEISIG, S.: MAYLES, H. M. O. Radiotherapy Physics in Practice. Oxford University Press. Cap. 10. Treatment verification an in vivo dosimetry. p. 227-251, 1999.

25 METCALFE. P.: KRON. T.: HOBAN. P. The Physics of Radiotherapy X-rays from Linear Accelerators. Medical Physics Publishing. Madison, Wisconsin, p. 91-228. 1997. 
26 MIJNHEER. B. J.; BATTERMANN, J. J.: WAMBERSIE. A. What degree of accurac! is required and can be achieved in photon and neutron trerapy?. Radiother. Oncol. v. 8 . p. 237-252. 1987.

27 NILSSON, B.; RUDÉN, B.-I.: SORCINI, B. Characteristics of silicon diodes as patient dosemeters in external radiation therapy. Radiother. Oncol., v. 11, p. 279-288. 1988.

28 RUDÉN B. -I Evaluation of the clinical use of TLD. Acta Radiol. Ther. Phys. Biol.. v. 15, p. 447-464. 1976.

29 RUDÉN B. -I Some applications of thermoluminescence dosimetry in medical and health physics. PhD Thesis, University of Stockholm, Stockholm. Sweden. 1975.

30 RUDÉN B. - I. and Nilsson B. Clinical dosimetry by means of thermoluminescent dosemeters. Proc. XIII Int. Congress of Radiology. Madrid. Excerpta Medica. Amsterdam, 2, p. 495, 1973.

31 RUDÉN B. -1. Two years experience of clinical thermoluminescence dosimetry at the Radiumhemmet. Proc. 3rd Int. Conf. on Luminescence Dosimetry. Risö. p. 781. 1971.

32 SUNTHARALINGAM, N.: MANSFIELD, C. M. Lithium fluoride dosimeters in clinical radiation dose measurements. Proc. 3rd Int. Conf. on Luminescence Dosimetry. Risö, p. 816, 1971.

33 SWINNEN. A.; VERSTRAETE, J.: HUYSKENS, D. P. Feasibility study of entrance in vivo dose measurements with mailed thermoluminescence detectors. Racliother. Oncol.. v. 73. p. 89-96, 2004.

34 TUNG. C. J.: WANG, H. C.; LO, S. H.; WU, J. M.; WANG, C. J. In vivo dosimetry for external photon treatments of head and neck cancers by diodes and TLDs. Rad. Protection Dosim.. p. 45-50. 2004.

35 VAN DAM J.; MARINELLO, G. Methods for in vivo dosimetry in external radiotherapy. ESTRO, Booklet Nr 1, Garant; 1994.

36 VENABLES. K.; MILES. E. A.; AIRD. E. G. A.; HOSKIN. P. J. The use of in vivo thermoluminescent dosimeters in the quality assurance programme for the START breast fractionation trial. Radiother. Oncol., v. 71. p. 303-310. 2004.

37 VIEGAS, C. C. B. Dosimetria in vivo com uso de detectores semicondutores e termoluminescentes aplicada ao tratamento de câncer de cabeça e pescoço. 2003. Dissertação de Mestrado. Universidade Federal do Rio de Janeiro. Rio de Janeiro.

38 WIKIPÉDIA, A ENCICLOPÉDIA LIVRE. Disponível em: $<$ http://pt.wikipedia.org/wiki/Imagem:Epoxy_prepolymer_chemical_structure.png $>$. Acesso em: 12 jul. 2005.

39 ZIMMERMAN. D. W.; RHYNER, C. R.: CAMERON. J. R. Thermal annealing effects on the thermoluminescence of LiF. Heath Phys., v. 12. p. 525-531, 1966. 


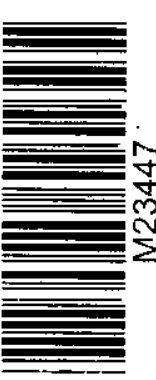

Instituto de Pesquisas Energéticas e Nucleares

Diretorla de Pesquisa, Desenvolvimento e Ensino

Av. Prof. Lineu Prestes, 2242 Cldade Universitária CEP: 05508-000

Fone/Fax(0XX11) $3816-9148$

SAO PAULO - S\%o Paulo - Brash

http: /hwm.ipen.br

O Ipen o uma autarqula vinculada a Secretaria de Ciencia, Tecnologla e Desenvolvimento Economlco - Turiemo do Eatado de Slo Paulo, gerlda tócnica, adminlatratlva e financelramente pela

Comiasto Nactonaj de Energla Nuclear, orgto do Ministorio da Cioncla e Tecnologla, esseclada Universidade de Stlo Paulo. 